\title{
Interaction of 5-hydroxy-L-tryptophan and negative dietary cation-anion difference on calcium homeostasis in multiparous peripartum dairy cows
}

\author{
C. J. Slater, ${ }^{*}$ E. L. Endres, ${ }^{*}$ S. R. Weaver, ${ }^{*}$ A. A. Cheng, ${ }^{*}$ M. R. Lauber, ${ }^{*}$ S. F. Endres, ${ }^{*}$ E. Olstad, ${ }^{*}$ A. DeBruin, ${ }^{*}$ \\ P. M. Crump, ${ }^{*}$ E. Block, $†$ and L. L. Hernandez ${ }^{* 1}$ \\ *Department of Dairy Science, University of Wisconsin, Madison 53706 \\ †Church and Dwight Co. Inc., Princeton, NJ 08453
}

\begin{abstract}
Hypocalcemia affects almost $50 \%$ of all dairy cows. Our laboratory has previously demonstrated that infusions of the serotonin precursor 5-hydroxy-L-tryptophan (5-HTP) increase circulating calcium concentrations in the Holstein transition cow. It is unknown whether feeding a negative dietary cation-anion difference (DCAD) diet alters the relationship between 5-HTP and hypocalcemia. The main objective of this study was to determine whether feeding a negative DCAD (-DCAD) diet before calving in conjunction with 5 -HTP treatment could further diminish the magnitude of hypocalcemia at the time of calving. We used a randomized complete block design with a $2 \times 2$ factorial arrangement. Thirty-one multiparous Holstein cows were fed either a positive $(+13 \mathrm{mEq} / 100 \mathrm{~g})$ or negative $(-13 \mathrm{mEq} / 100$ g) DCAD diet $21 \mathrm{~d}$ before parturition and were intravenously infused daily with saline or 5 -HTP $(1 \mathrm{mg} / \mathrm{kg})$ starting $7 \mathrm{~d}$ before the estimated date of parturition. Cows were blocked by parity and were randomly assigned to 1 of 4 treatment groups: positive DCAD plus saline, positive DCAD plus 5-HTP, negative DCAD plus saline, and negative DCAD plus 5-HTP, resulting in $\mathrm{n}=8$ per group. Total calcium (tCa), ionized calcium (iCa), and feed intake were recorded. The iCa was elevated prepartum in the -DCAD/5-HTP group compared with the other treatment groups as well as on d 0 and 1 postpartum. Although differences in tCa were not significant across the pre- or postpartum periods, tCa was numerically higher on d 0 and significantly higher on $\mathrm{d} 1$ in -DCAD/5-HTP cows compared with all other groups. Prepartum the -DCAD/5-HTP treatment group ate less than the other treatment groups; however, postpartum dry matter intake differences were not significant. These findings demonstrate that feeding a -DCAD diet in conjunction with 5-HTP prepartum can increase postpartum circulating iCa concentrations
\end{abstract}

Received October 4, 2017.

Accepted February 20, 2018

${ }^{1}$ Corresponding author: llhernandez@wisc.edu and therefore diminish the magnitude of hypocalcemia at the time of parturition.

Key words: dietary cation-anion difference, serotonin, calcium

\section{INTRODUCTION}

The periparturient period is one of the most high-risk periods of the dairy cow's life. During this time, as much as $50 \%$ of dairy cows are estimated to experience some degree of hypocalcemia (Reinhardt et al., 2011), with an additional $5 \%$ of all dairy cows being diagnosed with clinical hypocalcemia (USDA, 2007). Hypocalcemia and subclinical hypocalcemia have been described as gateway diseases leading to increased rates of ketosis, fatty liver, metritis, retained placenta (RP), displaced abomasum, and mastitis as well as negatively affecting potential production and increasing the risk of involuntary culling in the dairy herd (Seifi et al., 2011; Chamberlin et al., 2013; Goff, 2014). It is estimated that more than $\$ 550$ million is lost annually in milk production alone in the United States dairy industry due to hypocalcemia (Guard, 1996; Hare et al., 2006; USDA, 2017).

At parturition, the dam's rapidly increasing $\mathrm{Ca}$ demand exceeds the amount that she can consume to maintain Ca homeostasis. During late gestation, the dairy cow requires approximately 10 to $16 \mathrm{~g}$ of Ca per day. On d 1 of lactation, a cow loses approximately 23 $\mathrm{g}$ of $\mathrm{Ca}$ to colostrum production, 30 to $50 \mathrm{~g}$ of Ca per day within the first few days of lactation, and by peak production, Ca loss into the milk increases to roughly $80 \mathrm{~g} / \mathrm{d}$ (Horst et al., 2005). Total blood calcium (tCa) of a healthy adult cow is maintained within the range of 2.1 to $2.5 \mathrm{mM}$ (Goff, 2008) and it is estimated that the cow will deplete her Ca reservoir 7 to 10 times per day to meet the demand of peak milk production (Horst et. al, 2005). With increased Ca demands, the cow is required to increase absorption of $\mathrm{Ca}$ from the intestine, decrease loss of $\mathrm{Ca}$ into the urine, and increase mobilization of $\mathrm{Ca}$ from bone tissue to maintain $\mathrm{Ca}$ homeostasis, while also producing milk. 
Increased attention to and control of dietary levels of several key minerals as well as the introduction of anionic salts has had a significant effect on the reduction of hypocalcemia in the dairy industry (Block, 1984; USDA, 2007). However, with almost $50 \%$ of all dairy cows second lactation and greater affected by subclinical hypocalcemia, control and mitigation of subclinical hypocalcemia remains a concern for the dairy industry (Rodriguez et al., 2017).

Over the past several decades, a better understanding of Ca homeostasis during the periparturient period has emerged. Parathyroid hormone (PTH) and vitamin D metabolites are critical regulators of calcium balance in nonlactating states; however, lactating mammals require additional lactation specific mechanisms to achieve calcium homeostasis (Wysolmerski, 2012; Kovacs, 2017). In dairy cows, research has demonstrated that the release of PTH by the parathyroid gland reduces loss of urinary $\mathrm{Ca}$, increases bone resorption of $\mathrm{Ca}$, and increases the synthesis of $1,25(\mathrm{OH})_{2} \mathrm{D}_{3}$ to enhance intestinal Ca absorption (Horst et al., 1997). While it was once believed that PTH and vitamin D were the primary modulators of Ca mobilization regardless of the animal's physiological state, more recent work has shown that parathyroid hormone-related protein $(\mathbf{P T H r P})$ produced by the mammary tissue is critical in regulating calcium metabolism during lactation (Moseley et al., 1987; Sowers et al., 1996; Mather et al., 1999; VanHouten et al., 2003). However, evidence also indicates that colostral concentrations of PTHrP in cows are not different between healthy and paretic cows (Riond et al., 1996). Because the binding site for PTHrP on the PTH-receptor is homologous to that of PTH, this allows both hormones to induce common cellular signal transduction pathways through interaction with the same receptor (Wysolmerski, 2012). Feeding anionic salts to dairy cows lowers blood $\mathrm{pH}$, thereby altering the physiological structure of the PTH-receptor on osteoblast cells (Block, 1984; Goff, 2008). The conformational change of the PTH-receptor created by feeding the anionic salts is known to increase the ability of PTH to bind to its receptor, leading to increased $\mathrm{Ca}$ resorption from bone and increased synthesis of $1,25(\mathrm{OH})_{2} \mathrm{D}_{3}$. It is likely that this may also increase the ability of PTHrP to bind as well.

In recent years, increased attention has been directed toward understanding the role of the monoamine serotonin (5-hydroxytryptamine) on mammary gland and lactation physiology. Specifically, research has demonstrated a role for serotonin in regulating Ca homeostasis during lactation (Hernandez et al., 2012; Weaver et al., 2016). Laporta et al. (2013) and Weaver et at. (2016) have shown an increase in tCa concentrations during lactation in both rodents and cows when serotonin con- centrations are increased around the time of parturition through the administration of 5-hydroxy-L-tryptophan (5-HTP), the direct precursor for the synthesis of serotonin, which bypasses the use of the rate-limiting enzyme tryptophan hydroxylase 1 (Wang et al., 2002; Laporta et al., 2015; Weaver et al., 2016). Given previous research on serotonin and PTHrP during lactation, it seems necessary to explore this relationship further in the dairy cow, despite conflicting evidence (Laporta et al., 2013; Moore et al., 2015).

This experiment aims to determine if feeding a negative DCAD diet in combination with administration of 5-HTP prepartum increases postpartum blood Ca concentrations compared with feeding a negative DCAD diet alone. Our hypothesis is that feeding a negative DCAD diet in combination with the 5-HTP treatment prepartum will elevate postpartum maternal blood $\mathrm{Ca}$ concentrations more than either of these treatments alone.

\section{MATERIALS AND METHODS}

The College of Agriculture and Life Sciences Animal Care and Use Committee at the University of Wisconsin-Madison approved all experimental procedures used on animals in this study. Care and use protocol guidelines (A005316) were strictly followed for this experiment.

\section{Animals and Experimental Design}

Thirty-one healthy, multiparous Holstein cows (second through fifth lactation), of similar production level and lactation number (average lactation number 2.8 $\pm 0.3 ; \pm \mathrm{SEM}$ ), were used for this experiment. Cows were blocked by parity and average lactation number was not different between treatment groups. Cows enrolled on study did not have a previous history of transition-related disorders. Approximately 4 wk before the expected date of parturition, cows were transported to the Dairy Cattle Center, a tiestall facility, at the University of Wisconsin-Madison, allowing approximately $1 \mathrm{wk}$ for cows to acclimate to the facility. Feed intake was recorded daily by the farm staff. During this acclimation period, all cows were placed on a common herd dry cow diet, which was a low-energy, high-fiber, and low-DCAD diet consisting primarily of corn silage and straw, with no addition of anionic salts.

The experimental design was a randomized complete block design with a $2 \times 2$ factorial arrangement of treatments resulting in 4 treatment groups: positive DCAD plus saline (+DCAD/CON), positive DCAD diet plus 5-HTP (+DCAD/5-HTP), negative DCAD plus saline (-DCAD/CON), and negative DCAD plus 
Table 1. Ingredient composition of formulated prepartum diets

\begin{tabular}{|c|c|c|c|}
\hline \multirow[b]{2}{*}{ Ingredient (\% DM basis) } & \multicolumn{2}{|c|}{ Prepartum } & \multirow[b]{2}{*}{ Lactating } \\
\hline & $+\mathrm{DCAD}^{1}$ & $-\mathrm{DCAD}^{2}$ & \\
\hline Corn silage & 40.6 & 40.6 & 26.9 \\
\hline Alfalfa haylage & - & - & 23.8 \\
\hline Straw & 24.3 & 24.3 & - \\
\hline Fuzzy cottonseed & - & - & 5.8 \\
\hline Corn gluten feed & 13.8 & 13.8 & - \\
\hline Exceller Meal $^{3}$ & 8.1 & 5.7 & 4.8 \\
\hline Soybean meal & 8.1 & 4.8 & - \\
\hline Canola meal & - & - & 6.7 \\
\hline Distillers grain & - & - & 4.8 \\
\hline Soy hulls & - & - & 3.2 \\
\hline Fat & - & - & 0.3 \\
\hline Bio-Chlor ${ }^{4}$ & - & 7.3 & \\
\hline Ground corn & 2.4 & 1.6 & 21.0 \\
\hline Calcium carbonate & 1.1 & 1.3 & 1.1 \\
\hline Sodium bicarbonate & - & - & 0.8 \\
\hline Magnesium oxide & 0.4 & 0.1 & 0.1 \\
\hline Calcium sulfate & 0.3 & - & - \\
\hline Salt & 0.2 & - & - \\
\hline Urea & 0.2 & - & 0.2 \\
\hline Dry cow vitamin/mineral ${ }^{5,6}$ & 0.5 & 0.5 & - \\
\hline Lactating vitamin $/ \mathrm{mineral}^{7}$ & - & - & 0.4 \\
\hline \multirow{3}{*}{\multicolumn{4}{|c|}{$\begin{array}{l}{ }^{1}+\mathrm{DCAD} \text { was formulated to equal }+13 \mathrm{mEq} / 100 \mathrm{~g} \text { and } 5.9 \mathrm{~kg} \text { of water was added to this diet. } \\
{ }^{2}-\mathrm{DCAD} \text { was formulated to equal }-13 \mathrm{mEq} / 100 \mathrm{~g} \text { and } 5.9 \mathrm{~kg} \text { of water was added to this diet. } \\
{ }^{3} \text { Exceller Meal is a high-bypass, highly digestible soybean meal. Produced by Quality Roasting Inc. (Valders, } \\
\text { WI). }\end{array}$}} \\
\hline & & & \\
\hline & & & \\
\hline \multirow{2}{*}{\multicolumn{4}{|c|}{$\begin{array}{l}{ }^{4} \text { Bio-Chlor is a patented feed supplement for prepartum transition cows providing a source of degradable pro- } \\
\text { tein and dietary anions. Analysis on a DM basis (total } \mathrm{DM}=87.0 \% \text { ): } \mathrm{CP}=48.6 \%, \mathrm{~K}=1.2 \%, \mathrm{~S}=3.6 \% \text {, Na } \\
=1.5 \% \text {, and } \mathrm{Cl} \text { ion }=9.1 \% \text {. Produced by Arm and Hammer Animal Nutrition (Princeton, NJ). } \\
{ }^{5} \text { Rumensin (Elanco Animal Health, Greenfield, IN) included at a rate of } 16 \mathrm{mg} / \mathrm{kg} \text { of DM. }\end{array}$}} \\
\hline & & & \\
\hline \multicolumn{4}{|c|}{${ }^{6}$ Vitamin D included at a rate of 2,695 IU/kg of DM. } \\
\hline${ }^{7}$ Rumensin included at a rat & & & \\
\hline
\end{tabular}

5-HTP (-DCAD/5-HTP). An n $=8$ was used for each treatment group with exception of the $-\mathrm{DCAD} / 5$ HTP treatment group, which had an $\mathrm{n}=7$. The average number of days cows were on their respective treatment diet was $20.9 \pm 2.0 \mathrm{~d}$, and they received intravenous infusions an average of $7.9 \pm 1.7 \mathrm{~d}$, with no significant differences in number of days on diet or number of days infused between treatment groups.

Twenty-one days before the expected parturition date, cows were fed ad libitum 1 of 2 low-energy, high-fiber diets either with or without anionic salts. Cows were on their respective treatment diet until the day of parturition. The diet containing anionic salts $(-\mathrm{DCAD})$ was formulated to equal a DCAD of $-13 \mathrm{mEq} / 100 \mathrm{~g}$ and the diet without anionic salts (+DCAD) was formulated to equal a DCAD of $+13 \mathrm{mEq} / 100 \mathrm{~g}$. Formulated dry cow diets are shown in Table 1 . Seven days before expected date of parturition, cows were infused daily intravenously via jugular catheters at approximately $0800 \mathrm{~h}$ with either $1 \mathrm{~L}$ of saline or $1 \mathrm{~L}$ of saline containing $1 \mathrm{mg} / \mathrm{kg}$ of BW of 5 -HTP. This dose of 5 -HTP was selected based on results of previous studies in our laboratory (Laporta et al., 2015; Weaver et al., 2016).
Infusions were ceased at parturition, and all cows were placed on a common herd lactating diet (Table 1) and fed ad libitum until d 30 of lactation. Daily DMI was recorded daily prepartum and postpartum by recording the amount of feed offered and recording the amount left the following day when cows were offered fresh feed, and BW were recorded weekly. Milk yield was recorded daily during the postpartum period.

\section{Sample Collection}

Blood samples were collected via the coccygeal vein beginning on $\mathrm{d}-23$ relative to parturition (DRP) and continued through +30 DRP. Blood samples were obtained every $3 \mathrm{~d}$ between -23 and $-3 \mathrm{DRP}$, daily from -3 to +3 DRP, and every $3 \mathrm{~d}$ between +3 and +30 DRP. Approximately $8 \mathrm{~d}$ before the predicted parturition date, a jugular catheter was inserted in each cow and sutured to skin that had been previously clipped and scrubbed with betadine and $70 \%$ ethanol. Catheters were flushed with sterile saline containing 10 $\mathrm{IU} / \mathrm{mL}$ of heparin every $12 \mathrm{~h}$. On infusion days, blood samples were collected from the jugular catheter imme- 
diately before and following the infusion. To isolate the serum and plasma fractions of the blood, 10-mL Clot Activator BD Vacutainer Serum Plus tubes and 10-mL BD Vacutainer tubes (BD Biosciences, San Jose, CA) with lithium heparin were used. Samples were centrifuged at $3,000 \times \mathrm{g}$ for $20 \mathrm{~min}$ at $4^{\circ} \mathrm{C}$. Blood serum and plasma fractions were aliquoted and stored at $-80^{\circ} \mathrm{C}$ until analysis.

Urine samples were collected daily via manual stimulation of the skin under the vulva. Samples were collected mid-stream in 5-mL Eppendorf tubes (Hauppauge, NY). All urine samples were stored at $-20^{\circ} \mathrm{C}$ until analysis.

Mammary gland biopsies were collected on d 1 and 8 of lactation. To obtain biopsies, cows were sedated with $0.02 \mathrm{mg} / \mathrm{kg}$ of butorphanol (Torbugesic, Zoetis, Parsippany, NJ) and $0.02 \mathrm{mg} / \mathrm{kg}$ of xylazine (Vedco, St. Joseph, MO). Hair was removed from the udder and the surgical site was scrubbed using betadine surgical scrub (Purdue Products, Stamford, CT) and $70 \%$ ethanol. Local anesthesia was achieved using $5 \mathrm{~mL}$ of $2 \%$ lidocaine (VetOne, Boise, ID) at the biopsy site. The biopsy site was located approximately $5 \mathrm{~cm}$ above the gland cistern in a location where minimal superficial veins were visible. Using a scalpel blade, a $1.5-\mathrm{cm}$ incision was made through the udder, muscle, and connective tissue layers to reach the parenchymal tissue. Using an 8-mm sterile disposable biopsy punch (Miltex, Cary, NC), parenchymal tissue was obtained (approximately $0.8-1.3 \mathrm{~g}$ ). The inner layer of connective tissue was surgically closed using a 2-0 monocryl absorbable suture (Ethicon, New Brunswick, NJ) and then the skin layer was closed using 2-0 ethilon nonabsorbable sutures (Ethicon). Biopsy sites were alternated between the 2 rear quarters of the cow. Sutures were monitored daily for signs of infection and were removed $10 \mathrm{~d}$ after the biopsy.

Feed samples were collected weekly for wet chemistry analysis. Feeds collected included corn silage, straw, +DCAD TMR, -DCAD TMR, and lactation TMR (Table 1). Freshly collected feed samples were pooled within animals and were sent to Rock River Laboratories Inc. (Watertown, WI) for immediate wet chemistry analysis twice weekly. The weekly TMR analyses were averaged following completion of the trial (Table 2). Actual diets in terms of DCAD were different than the diets designed.

\section{Sample Evaluation}

Serum blood samples were used to determine both tCa and serotonin concentrations. The tCa concentrations were determined using a colorimetric calcium assay kit (\#700550, Cayman Chemical, Ann Arbor, MI) per the manufacturer's instructions (https://www .caymanchem.com/product/701220). The intra- and interassay coefficients of variation $(\mathbf{C V})$ for tCa were 3.7 and $2.5 \%$, respectively. Serotonin enzyme immunoassays (\#IM1749, Immunotech, Beckman Coulter, Brea, $\mathrm{CA}$ ) were used to determine serotonin concentrations.

Table 2. Analyzed chemical composition of diets based on average of analyzed weekly samples

\begin{tabular}{|c|c|c|c|}
\hline \multirow[b]{2}{*}{ Item } & \multicolumn{2}{|c|}{ Prepartum ${ }^{1}$} & \multirow[b]{2}{*}{ Lactating $^{2}$} \\
\hline & $+\mathrm{DCAD}$ & $-\mathrm{DCAD}$ & \\
\hline \multicolumn{4}{|l|}{ Nutrient (\% DM as fed) } \\
\hline $\mathrm{DM}$ & 44.5 & 45.5 & 54.9 \\
\hline $\mathrm{CP}$ & 14.9 & 15.3 & 18.2 \\
\hline aNDF & 42.7 & 41.4 & 32.0 \\
\hline $\mathrm{ADF}$ & 27.1 & 26.5 & 22.6 \\
\hline Starch & 19.0 & 19.1 & 21.9 \\
\hline NFC & 33.9 & 34.6 & 39.2 \\
\hline Fat & 2.6 & 2.6 & 4.6 \\
\hline Ash & 7.7 & 7.8 & 7.7 \\
\hline $\mathrm{Ca}$ & 0.56 & 0.59 & 0.86 \\
\hline $\mathrm{P}$ & 0.32 & 0.32 & 0.39 \\
\hline $\mathrm{Mg}$ & 0.30 & 0.32 & 0.31 \\
\hline $\mathrm{K}$ & 1.28 & 1.26 & 1.34 \\
\hline $\mathrm{Na}$ & 0.15 & 0.13 & 0.38 \\
\hline $\mathrm{S}$ & 0.20 & 0.33 & 0.20 \\
\hline $\mathrm{Cl}$ & 0.47 & 0.81 & 0.35 \\
\hline $\mathrm{DCAD}^{3}(\mathrm{mEq} / 100 \mathrm{~g}$ of $\mathrm{DM})$ & 14.0 & -5.5 & 28.7 \\
\hline \multicolumn{4}{|l|}{ NRC (2001) energy calculations } \\
\hline TDN $1 \times$ & 64.91 & 64.49 & 70.75 \\
\hline $\mathrm{NE}_{\mathrm{L}} 3 \times(\mathrm{Mcal} / \mathrm{kg})$ & 1.47 & 1.47 & 1.63 \\
\hline
\end{tabular}

${ }^{1}$ Prepartum diet fed ad libitum from $\mathrm{d}-21$ to 0 relative to parturition.

${ }^{2}$ Lactating diet fed ad libitum from d 1 to 30 relative to parturition.

${ }^{3} \mathrm{DCAD}=(\mathrm{Na}+\mathrm{K})-(\mathrm{Cl}+\mathrm{S})$. 
All samples were diluted 1:100 to fit within the assay's standard curve range as previously described by our laboratory, and manufacturer's instructions were followed (Laporta et al., 2015; Moore et al., 2015; Weaver et al., 2016). The intra- and inter-assay CV for serotonin were 9.0 and $5.7 \%$, respectively.

Deoxypyridinoline (DPD) was measured in urine using an enzyme immunoassay (\#807, DPD MicroVue Bone Health). Samples were diluted 1:10 to fit within the standard curve. The DPD concentrations were corrected against creatinine concentrations in the urine to account for varying urine volumes. Creatinine concentrations were determined using a colorimetric assay per the manufacturer's instructions (\#DICT-500, QuantiChrom Creatinine Assay Kit, BioAssay Systems, Hayward, CA). The intra- and interassay CV for DPD were 6.3 and $4.7 \%$, respectively.

Ionized $\mathrm{Ca}$ (iCa), blood $\mathrm{pH}$, and blood hematocrit were determined immediately following blood sample collection using a handheld VetScan i-STAT (Abbott Company, Princeton, NJ). Immediately following urine collection, urine $\mathrm{pH}$ was determined using the LAQUA Twin $\mathrm{pH}$ Meter (Horiba, Irvine, CA).

Total RNA was extracted from mammary gland tissue using TRI-Reagent (\#TR118, Molecular Research, Cincinnati, OH) and the Tissue Master 125 Homogenizer (Omni International, Kennesaw, GA). The RNA was quantified using a Nanodrop Spectrophotometer 200C (Thermo Scientific, Waltham, MA). The purity of the RNA as evaluated by the A260/A280 ratio was between 1.8 to 2.0. One microgram of RNA was reverse transcribed to cDNA using Bio-Rad iScript Reverse Transcription Supermix (\#1708840, Bio-Rad, Hercules, CA) following the manufacturer's instructions. Quantitative RT-PCR was conducted with the CFX96 Touch Real-Time PCR Detection System (Bio-Rad). Reaction mixtures and cycling conditions were performed as previously described (Laporta et al., 2015). All primers were designed to span exon-exon junctions and for an optimal annealing temperature of $60^{\circ} \mathrm{C}$. Amplification efficiencies of primers were accepted within a range of
95 to $105 \%$ efficiency, and primer specificity was assessed by the presence of a single temperature dissociation peak, eliminating and redesigning any primers with indication of secondary structures. Mammary gland tissue mRNA was evaluated for parathyroid hormone related-protein $(\boldsymbol{P} \boldsymbol{T H} \boldsymbol{r} \boldsymbol{P})$, calcium release-activated calcium channel 1 ( ORAI1), plasma membrane $\mathrm{Ca}^{2+}$ ATPase $2(\boldsymbol{P M C A 2})$, secretory pathway $\mathrm{Ca}^{2+}$ ATPase isoform 1 (SPCA1), proliferating nuclear antigen $(\boldsymbol{P C N A})$, and $\alpha$-LA. Primer sequences can be found in Table 3. The geometric means of ribosomal protein 15 (RPS15), cyclophilin A (CYCLOA), and hypoxanthine phosphoribosyltransferase 1 (HPRT1) were used as housekeeping genes, and analysis was conducted using the $2^{-\Delta \Delta \mathrm{Ct}}$ method (Livak and Schmittgen, 2001). The housekeeping genes RPS15, CYCLOA, and HPRT1 were chosen due to the narrow range of cycle threshold values encompassing all samples. To examine the difference in gene expression between diets and treatments using the $2^{-\Delta \Delta \mathrm{Ct}}$ method, all treatment groups were analyzed relative to the $+\mathrm{DCAD} / \mathrm{CON}$ d 1 mammary gland cycle threshold values as the internal control.

\section{Statistical Analysis}

A linear mixed model with repeated measures was used to complete analysis of the data using SAS software (version 9.3, SAS Institute Inc., Cary, NC). Prepartum and postpartum time periods were analyzed separately. The model used was $\mathrm{Y}=\mathrm{T}+\mathrm{A}+\mathrm{T} \times \mathrm{A}+\operatorname{cow}(\mathrm{T} \times \mathrm{A})$ $+\mathrm{D}+\mathrm{D} \times \mathrm{T}+\mathrm{D} \times \mathrm{A}+\mathrm{D} \times \mathrm{T} \times \mathrm{A}+\mathrm{e}$, where $\mathrm{T}$ was the fixed effect of treatment with saline or 5-HTP, A was the fixed effect of the diet (+DCAD or -DCAD), D was the fixed effect of the DRP, with parturition as d 0 , and e was the error. The random effect of cow within treatment was considered the error term for all effects that did not include the day effect. To account for autocorrelated errors due to repeated measurements on the same experimental unit, $\operatorname{cow}(\mathrm{T} \times \mathrm{A})$, an $\mathrm{sp}(\mathrm{pow})$ error structure was used within the SAS MIXED procedure. The residuals from the model were analyzed with a nor-

Table 3. Primer sequences used for real-time quantitative PCR

\begin{tabular}{lll}
\hline Primer $^{1}$ & Forward $\left(5^{\prime}\right.$ to $\left.3^{\prime}\right)$ & Reverse $\left(5^{\prime}\right.$ to $\left.3^{\prime}\right)$ \\
\hline Parathyroid hormone-related protein & GGAGGCTAGTTCAGCAATGG & CCGAGGTAGCTCTGATTTCG \\
Calcium release activated calcium channel protein 1 & GGCGCAAACTCTACTTGAGC & GGTAGTCGTGGTCAGCATCC \\
Plasma membrane calcium ATPase2 & CATCAAGTGTGGCATCATCC & TGGCCAGATCTTATCGATCC \\
Calcium-transporting ATPase type 2C member 1 & TGCTCTTGCAATGAAGATGG & CGGTGCACACACTTAACAGC \\
Proliferating cell nuclear antigen & CCCTTGAAGGATGAAAATGG & TCCCTAACACACCAGGAAGG \\
o-LA & CTCTGCTCCTGGTAGGCATC & ACAGACCCATTCAGGCAAAC \\
Ribosomal protein 15 & CGCGACATGATCATTCTACC & TTACTTGTGGGGGATGAAGC \\
Cyclophilin A & CACCGTGTTCTTCGACATCG & ACAGCTCAAAAGAGACGCGG \\
\hline
\end{tabular}

\footnotetext{
${ }^{1}$ The primers were designed using Primer3plus (http://primer3plus.com), and the sequences were obtained from GenBank (http://www.ncbi.
} nlm.nih.gov). 
mality test, and when the normality assumption failed, the ranks of the data were analyzed in a nonparametric matter. Each metabolite and gene was evaluated for extreme influential data points and outliers, which were removed when identified. In the analyses of serotonin, a covariate correction was necessary. The covariate used was a baseline average of 2 daily blood samples taken before any treatment including diet was applied to the cow. For all analyses, differences between means were considered significant at $P \leq 0.05$ and were considered a tendency when $0.05<P<0.10$. All values are reported as least squares means \pm standard error of the mean.

\section{RESULTS}

The time-dependent pattern of all variables and treatment groups are presented in Figures 1-6. The chemical composition of the experimental diets is presented in Table 2 . The analyzed DCAD $[(\mathrm{Na}+\mathrm{K})-(\mathrm{Cl}$ $+\mathrm{S})]$ value of the + DCAD prepartum diet, - DCAD prepartum diet, and the lactating diet were 14.0, -5.5, and $28.8 \mathrm{mEq} / 100 \mathrm{~g}$, respectively.

Disease incidences were recorded throughout the experiment. Of the 31 cows enrolled in the study, 1 $+\mathrm{DCAD} / \mathrm{CON}, 2+\mathrm{DCAD} / 5-\mathrm{HTP}$, and $1-\mathrm{DCAD} /$ $\mathrm{CON}$ cows were treated for ketosis. One $+\mathrm{DCAD} / 5$ HTP cow and $2-\mathrm{DCAD} / \mathrm{CON}$ cows were treated for mastitis. One $+\mathrm{DCAD} / \mathrm{CON}$ was treated for a RP. Finally, $1+\mathrm{DCAD} / \mathrm{CON}$ and $1+\mathrm{DCAD} / 5-\mathrm{HTP}$ required treatment with intravenous calcium due to clinical symptoms of hypocalcemia. The - DCAD/5-HTP combination had the least number of adverse health events postpartum and least number of subclinically hypocalcemic cows. Based on the current definition of subclinical hypocalcemia (tCa 1.4 to $2.0 \mathrm{mM}$ ), 3 of 7 -DCAD/5-HTP cows and 5 of $8-\mathrm{DCAD} / \mathrm{CON}$ cows had subclinical hypocalcemia. No cow on the -DCAD diet dropped below $1.4 \mathrm{~m} M$. Fifteen of the $16+$ DCAD cows dropped below $2.0 \mathrm{mM}$, with 2 of the $+\mathrm{DCAD} / 5$ HTP cows and 1 of the $+\mathrm{DCAD} / \mathrm{CON}$ cows dropping below $1.4 \mathrm{~m} M$, into the clinical hypocalcemia range.

\section{Total Ca Concentrations}

The tCa concentrations (Figure 1A) decreased in all groups $(P<0.0001)$ during the prepartum period. On d 0 (parturition), tCa concentrations of the $-\mathrm{DCAD}$ group were higher than the + DCAD group $(P<0.05)$ with values of $1.68 \pm 0.08,1.91 \pm 0.07,1.89 \pm 0.06$, and $2.11 \pm 0.07 \mathrm{mM}$ for $+\mathrm{DCAD} / \mathrm{CON},+\mathrm{DCAD} / 5-$ $\mathrm{HTP},-\mathrm{DCAD} / \mathrm{CON}$, and $-\mathrm{DCAD} / 5$-HTP, respectively. The day of the parturition tCa reached its nadir in the $-\mathrm{DCAD} / 5-\mathrm{HTP},+\mathrm{DCAD} / \mathrm{CON}$, and $+\mathrm{DCAD} / 5-$
HTP cows. Total Ca of the -DCAD/5-HTP cows was increased compared with all other groups on $\mathrm{d} 1$ of lactation $(P=0.05)$ at $2.11 \pm 0.08 \mathrm{mM}$. Total $\mathrm{Ca}$ of the $-\mathrm{DCAD} / \mathrm{CON}(1.89 \pm 0.06 \mathrm{~m} M)$ and $+\mathrm{DCAD} / 5-$ $\mathrm{HTP}(1.91 \pm 0.06 \mathrm{mM})$ were both increased $(P=0.05)$ relative to the $+\mathrm{DCAD} / \mathrm{CON}(1.68 \pm 0.08 \mathrm{mM})$, but were not different from each other.

\section{Ionized Ca Concentrations}

The iCa concentrations (Figure 1B) decreased during the prepartum period in all groups $(P<0.0001)$. Additionally, there were prepartum effects of DCAD $(P$ $<0.01)$, 5 -HTP $(P<0.05)$, and a DCAD by 5 -HTP interaction $(P<0.05)$ on iCa concentrations. Across the prepartum period, $-\mathrm{DCAD} / 5-\mathrm{HTP}$ cows had the highest iCa values compared with all other treatments. Postpartum, a day effect $(P<0.0001)$ was present, as well as a DCAD by day interaction $(P<0.01)$. Most notable were the $\mathrm{iCa}$ concentrations on $\mathrm{d} 0$ and 1 in the -DCAD/5-HTP group, which were elevated $(P<$ 0.05 and $P<0.01$, respectively) with a value of 1.20 $\pm 0.03 \mathrm{~m} M$ on both $\mathrm{d} 0$ and $1.21 \pm 0.04 \mathrm{~m} M \mathrm{~d} 1$ compared with the other 3 treatments (iCa on $\mathrm{d} 0$ and 1, respectively: $+\mathrm{DCAD} / \mathrm{CON}, 1.00 \pm 0.03$ and 1.03 $\pm 0.03 \mathrm{mM} ;+\mathrm{DCAD} / 5$-HTP, $1.05 \pm 0.04$ and $1.05 \pm$ $0.04 \mathrm{~m} M ;-\mathrm{DCAD} / \mathrm{CON}, 1.10 \pm 0.03$ and $1.08 \pm 0.03)$.

\section{Urine and Blood pH}

Urine $\mathrm{pH}$ (Figure 2A) was significantly different between + DCAD and -DCAD treatment groups prepartum $(P<0.0001)$ as well as postpartum $(P<0.01)$. A DCAD by day interaction was observed in both the prepartum and postpartum periods $(P<0.001$ and $P$ $<0.01$, respectively), as well as a day effect postpartum $(P<0.0001 ;$ Figure 3). Prepartum, the mean urine $\mathrm{pH}$ for each of the groups were as follows: $8.19 \pm 0.08$, $8.10 \pm 0.08,5.91 \pm 0.08$, and $5.82 \pm 0.09$ for $+\mathrm{DCAD} /$ $\mathrm{CON},+\mathrm{DCAD} / 5-\mathrm{HTP},-\mathrm{DCAD} / \mathrm{CON},-\mathrm{DCAD} / 5-$ HTP, respectively. Postpartum, the mean urine $\mathrm{pH}$ for each of the groups was as follows: $8.27 \pm 0.04,8.21 \pm$ $0.04,8.02 \pm 0.04$, and $7.88 \pm 0.04$ for $+\mathrm{DCAD} / \mathrm{CON}$, $+\mathrm{DCAD} / 5-\mathrm{HTP},-\mathrm{DCAD} / \mathrm{CON}$, and $-\mathrm{DCAD} / 5-\mathrm{HTP}$, respectively. This indicates that feeding of the $-\mathrm{DCAD}$ diet resulted in the typical drop in urine $\mathrm{pH}$ as one would expect based on this dietary strategy. No difference was observed in urine $\mathrm{pH}$ between the -DCAD/ $\mathrm{CON}$ and $-\mathrm{DCAD} / 5-\mathrm{HTP}$ groups. Despite the actual DCAD diets being -5.5 and +14 , rather than the -13 and +13 formulated, the urine $\mathrm{pH}$ results indicate that cows on the -DCAD diet were receiving sufficient anionic salts compared with the $+\mathrm{DCAD}$ diet. 

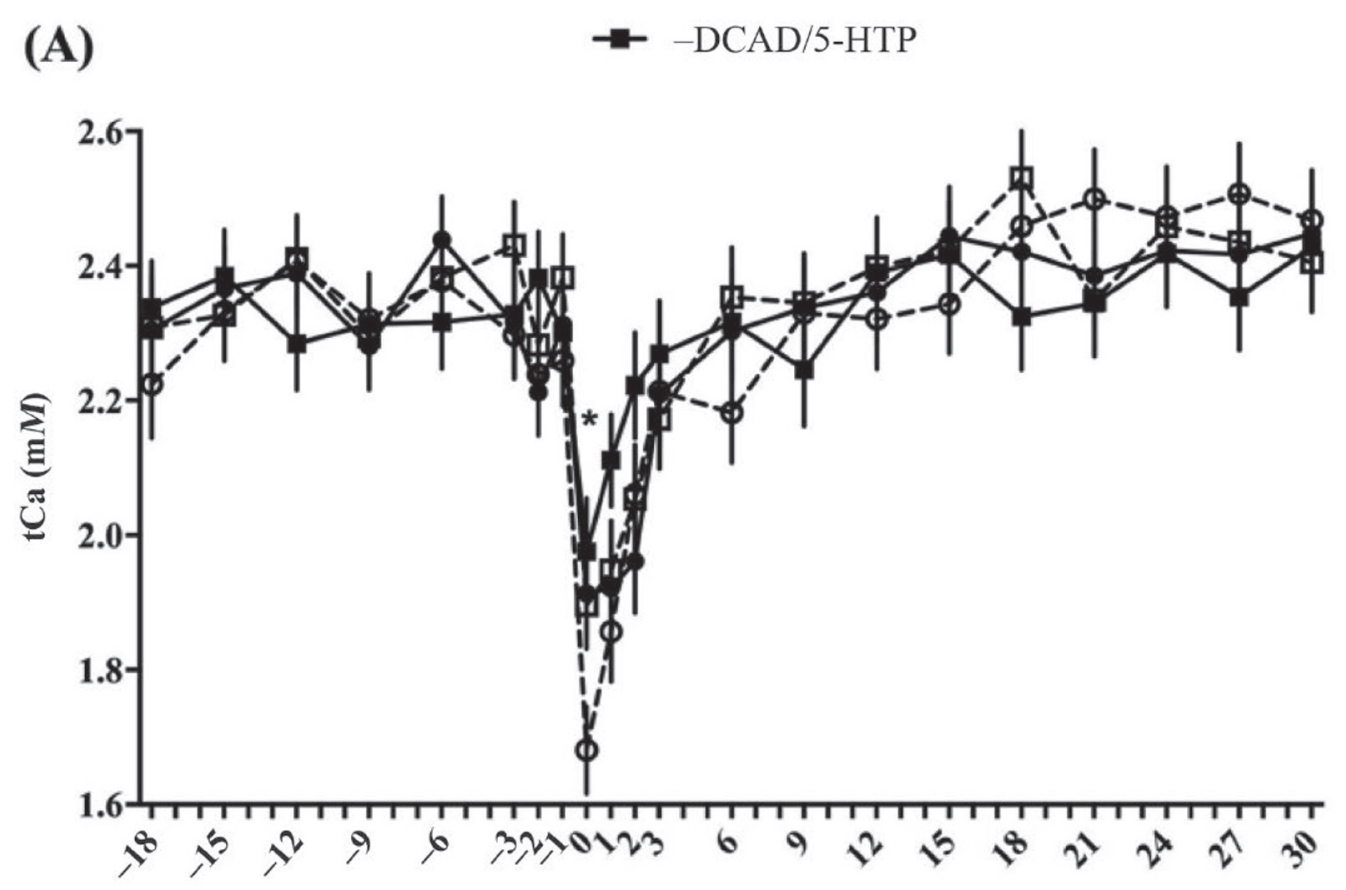

(B)

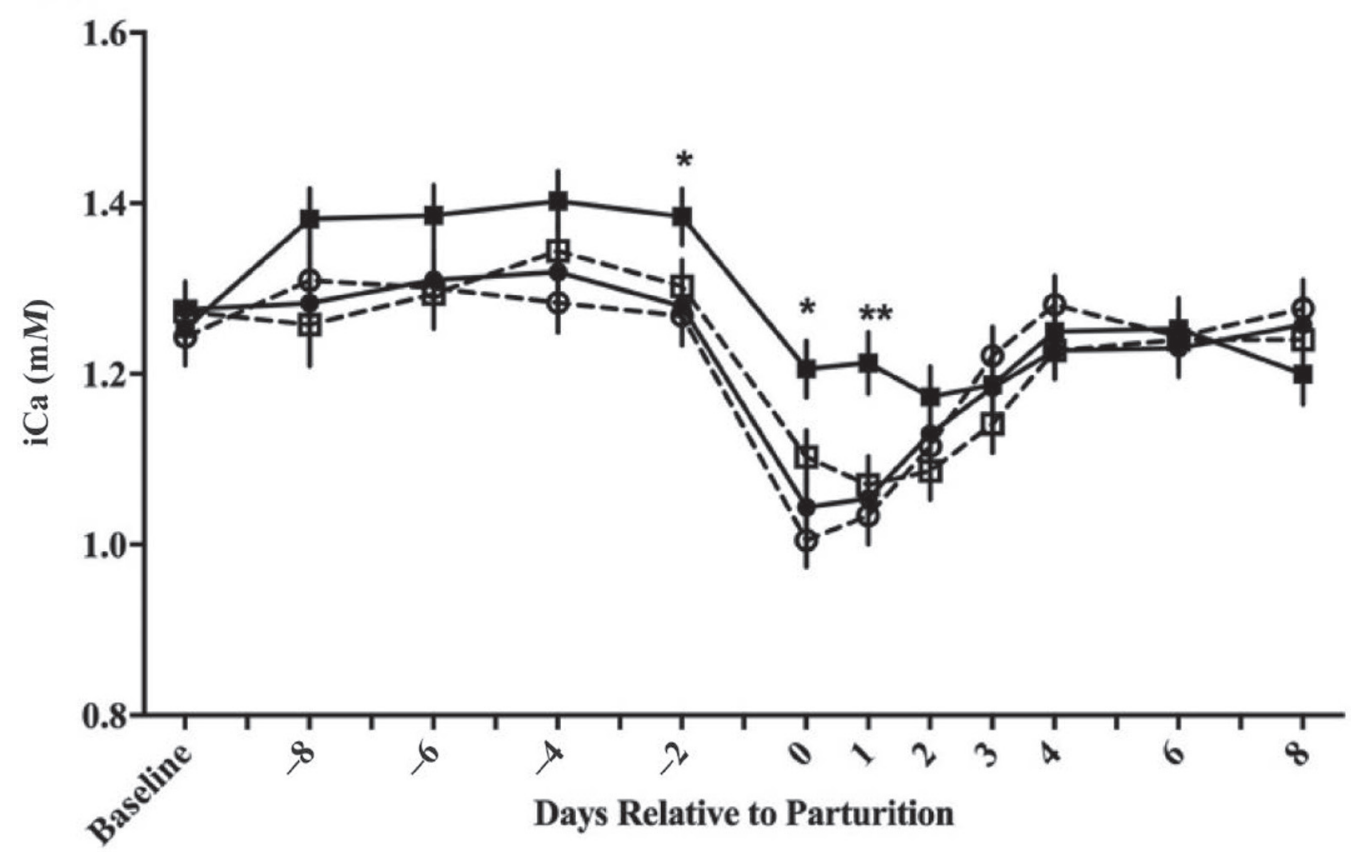

Figure 1. Effects of feeding a negative DCAD diet to multiparous Holstein dairy cows in combination with the delivery of 5-hydroxy-Ltryptophan (5-HTP) prepartum on total calcium (tCa) concentrations in serum (A) and ionized calcium (iCa) concentrations in blood (B). Prepartum, tCa was only significantly affected by time $(P<0.0001)$. For tCa postpartum, the $-\mathrm{DCAD} / 5$-HTP treatment group was increased on d $1(P=0.05)$. Asterisks indicate statistical significance between groups $(* P<0.05)$. For iCa prepartum (DCAD: $P<0.01,5$-HTP: $P<$ $0.05, \mathrm{DCAD} \times 5$-HTP,$P>0.05)$. Asterisks indicate statistical significance between groups $(* P<0.05)$. Data represent the LSM \pm SEM. CON $=$ saline. ${ }^{* *} P<0.01$. 


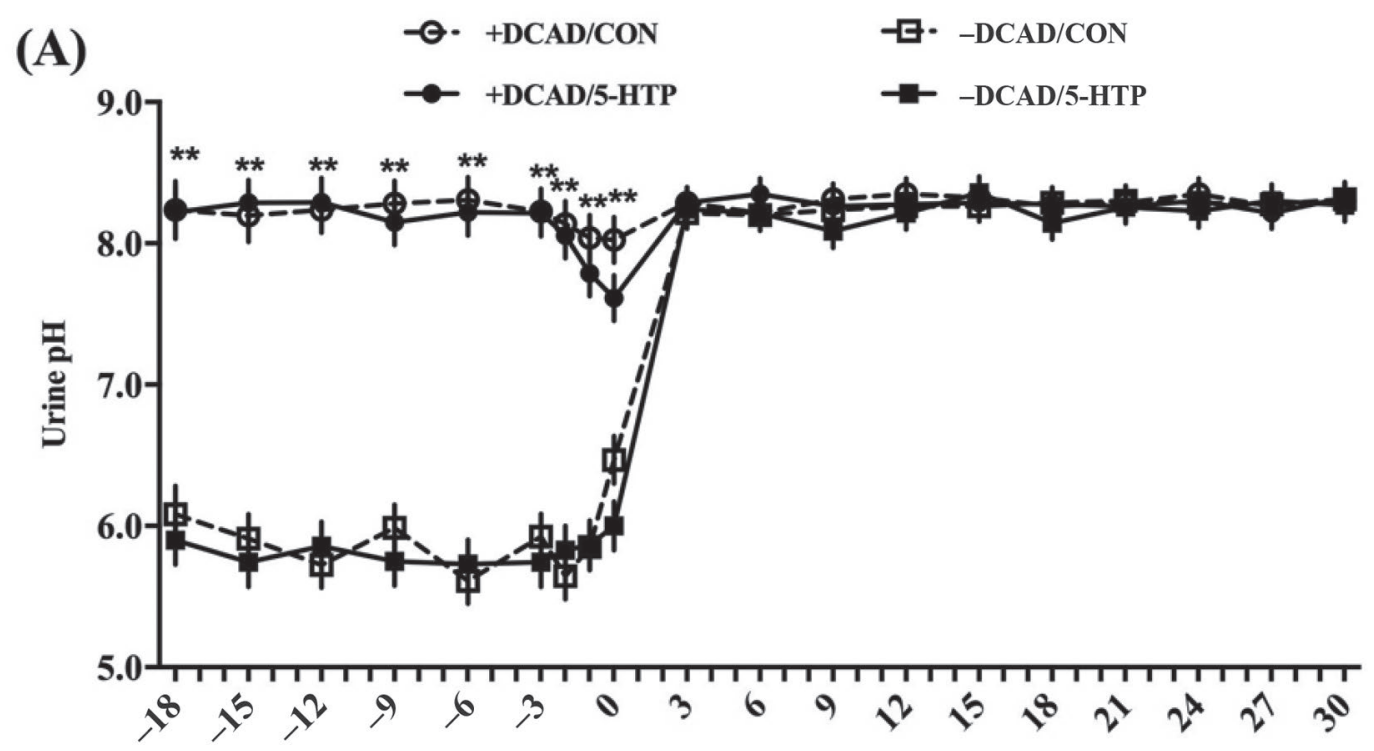

(B)

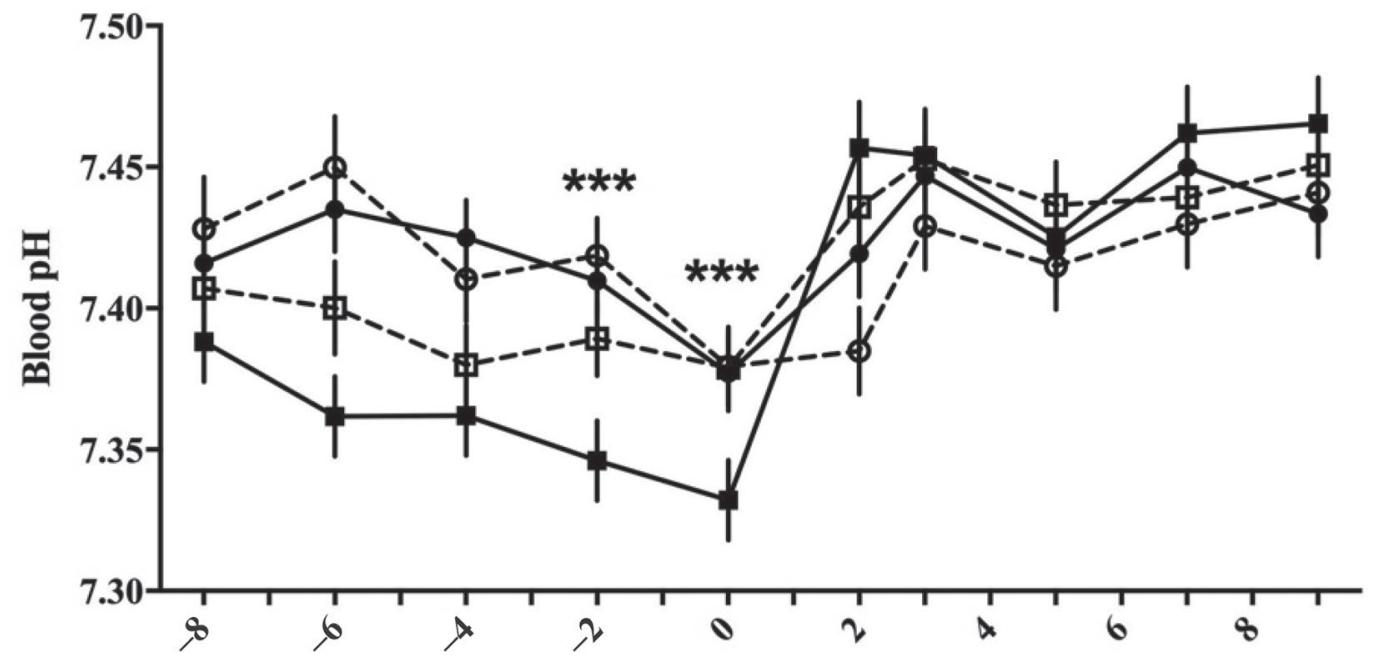

Days Relative to Parturition

Figure 2. Effects of feeding a negative DCAD diet to multiparous Holstein dairy cows in combination with the delivery of 5-hydroxy-Ltryptophan $(5-\mathrm{HTP})$ prepartum on urine $\mathrm{pH}(\mathrm{A})$ and whole blood $\mathrm{pH}(\mathrm{B})$. For urine $\mathrm{pH}$ prepartum $(\mathrm{DCAD}: P<0.0001, \mathrm{DCAD} \times$ day: $P=$ 0.001), postpartum (day: $P<0.0001$, DCAD: $P<0.01$, DCAD $\times$ day: $P<0.01$ ). For whole blood pH, prepartum (DCAD: $P<0.0001,5$-HTP: $P<0.05, \mathrm{DCAD} \times 5$-HTP: $P<0.05$ ) and postpartum (day: $P<0.0001$ ). Asterisks indicate statistical significance between for the DCAD $\times$ 5 -HTP interaction $\left({ }^{* *} P<0.01,{ }^{* * *} P<0.001\right)$. Data represent LSM $\pm \mathrm{SEM}$. CON $=$ saline.

Prepartum blood $\mathrm{pH}$ (Figure 2B) was decreased $(P<$ $0.0001)$ in the $-\mathrm{DCAD}$ diet $(7.375 \pm 0.006)$ compared with the + DCAD diet $(7.415 \pm 0.006)$. Prepartum blood $\mathrm{pH}$ was also decreased $(P<0.05)$ in the cows infused with 5 -HTP $(7.385 \pm 0.006)$ compared with the cows infused with saline $(7.404 \pm 0.006)$. Additionally, the $-\mathrm{DCAD} / 5$-HTP cows had a decreased $(P<0.05)$ blood $\mathrm{pH}(7.358 \pm 0.009)$ during the prepartum infusion period compared with all other treatment groups $(7.417 \pm 0.009,7.412 \pm 0.008$, and $7.391 \pm 0.009$ for
$+\mathrm{DCAD} / \mathrm{CON},+\mathrm{DCAD} / 5-\mathrm{HTP},-\mathrm{DCAD} / \mathrm{CON}$, respectively). In regard to postpartum blood $\mathrm{pH}$, a day effect $(P<0.0001)$ was observed, with blood $\mathrm{pH}$ rising in all groups between d 0 and 3 postpartum.

\section{Serotonin and Hematocrit}

Prepartum and postpartum serum serotonin concentrations increased with administration of 5-HTP $(P<$ 0.0001 ; Figures $3 \mathrm{~A}$ and $3 \mathrm{~B}$ ) with a prepartum mean 
(A)

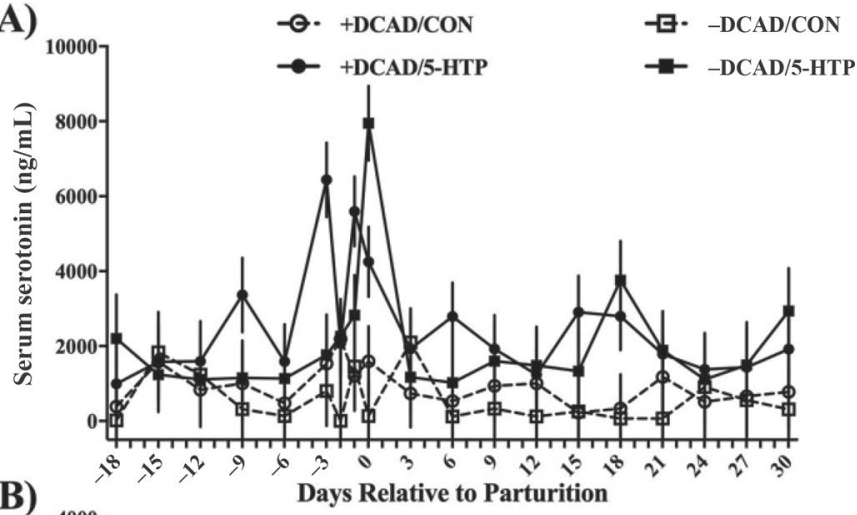

(B)

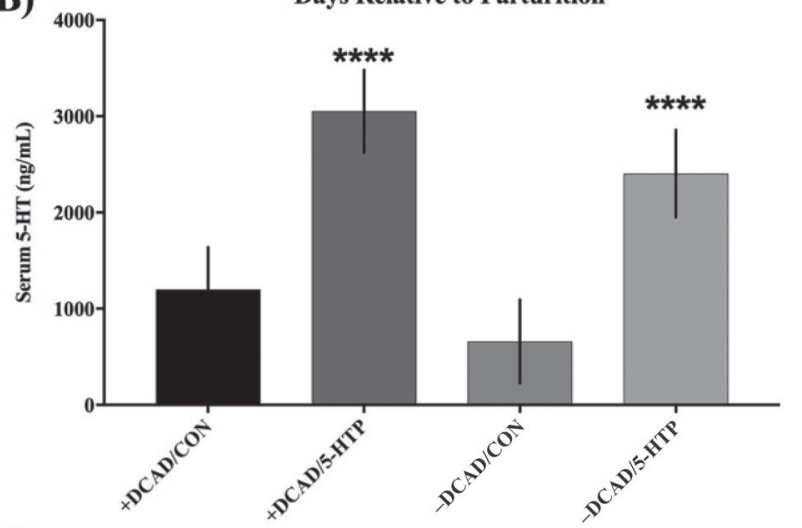

(C)

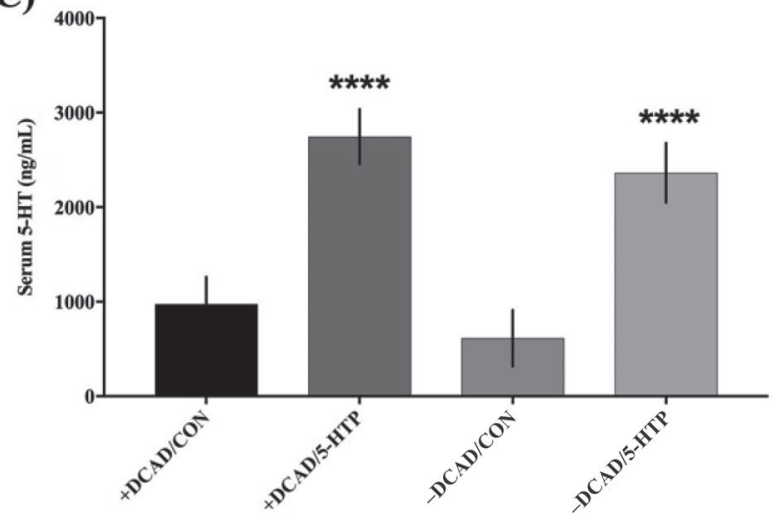

Figure 3. Effects of feeding a negative DCAD diet to multiparous Holstein dairy cows in combination with the delivery of 5-hydroxyL-tryptophan (5-HTP) prepartum on daily covariate adjusted serum serotonin concentrations $(\mathrm{A})$, and on the covariate adjusted mean serum serotonin concentrations prepartum (B) and postpartum (C). For daily covariate adjusted serum serotonin concentrations, prepartum (5-HTP: $P<0.0001$, day: $P<0.01$ ) and postpartum (5-HTP: $P<$ 0.0001$, DCAD $\times 5$-HTP: $P<0.05)$. For the mean serotonin concentrations, prepartum (5-HTP: $P<0.0001$, day: $P<0.01$ ) and postpartum (5-HTP: $P<0.0001$, DCAD $\times 5$-HTP: $P<0.05)$. Asterisks indicate statistical significance for the DCAD $\times 5$-HTP interaction $(* * * * P<0.0001)$. Data represent $\mathrm{LSM} \pm \mathrm{SEM} . \mathrm{CON}=$ saline.

of $2,728.5 \pm 312.3 \mathrm{ng} / \mathrm{mL}$ in the 5 -HTP infused cows, whereas the saline-infused cows averaged $930.1 \pm 308.9$ $\mathrm{ng} / \mathrm{mL}$. There was also a day effect prepartum $(P<$ 0.01 ; Figure $3 \mathrm{~A})$. Postpartum, a DCAD by 5 -HTP in- teraction was observed $(P<0.05)$, as well as a 5 -HTP effect $(P<0.0001$; Figure 3C). Postpartum means were similar to prepartum with $2,554.3 \pm 214.2 \mathrm{ng} / \mathrm{mL}$ in the 5-HTP-treated cows and $794.9 \pm 206.9 \mathrm{ng} / \mathrm{mL}$ in the saline-treated cows, with the 5-HTP cows having elevated serotonin concentrations compared with the saline-treated cows.

Normal bovine hematocrit values are in the range of 25 to $33 \%$. Hematocrit values were measured to determine that there was no hemoconcentration due to dehydration that possibly could be induced by the IV 5 -HTP treatments. Hematocrit values were not different between the 4 treatment groups during any part of the experiment. A tendency was observed for a DCAD by 5 -HTP interaction $(P=0.10)$. Hematocrit concentrations did increase from $25.7 \pm 0.4 \mathrm{~m} M$ on $\mathrm{d}-8$ to $28.4 \pm 0.4 \mathrm{~m} M$ on $\mathrm{d} 0(P<0.0001)$ and then decreased postpartum from $28.4 \pm 0.5 \mathrm{~m} M$ on d 0 to $22.3 \pm 0.5$ $\mathrm{m} M$ on d $9(P<0.0001)$ postpartum.

\section{Urine DPD}

In this experiment, urine DPD concentrations (Figure 4) did not differ between any of the 4 treatment groups either prepartum or postpartum; however, a day effect was observed postpartum $(P<0.0001)$, with urine DPD increasing in all groups between $\mathrm{d} 3$ and 6 postpartum. Prepartum mean urine DPD concentrations were as follows: $5.0 \pm 0.5,4.8 \pm 0.5,3.9 \pm 0.5$, and $4.8 \pm 0.5 \mathrm{~m} M$ for $+\mathrm{DCAD} / \mathrm{CON},+\mathrm{DCAD} / 5-\mathrm{HTP}$, $-\mathrm{DCAD} / \mathrm{CON}$, and $-\mathrm{DCAD} / 5-\mathrm{HTP}$, respectively. Postpartum mean urine DPD concentrations were as follows: $7.7 \pm 0.7,7.5 \pm 0.6,6.6 \pm 0.7$, and $7.7 \pm 0.7$ $\mathrm{m} M$, for $+\mathrm{DCAD} / \mathrm{CON},+\mathrm{DCAD} / 5-\mathrm{HTP},-\mathrm{DCAD} /$ $\mathrm{CON}$, and $-\mathrm{DCAD} / 5-\mathrm{HTP}$, respectively.

\section{Milk Yield}

Daily milk yield (Figure 5A) increased significantly in all groups $(P<0.0001)$ from parturition to $\mathrm{d} 30$ postpartum. A DCAD by 5 -HTP interaction $(P<0.05)$ was observed. The $+\mathrm{DCAD} / 5-\mathrm{HTP}$ and $-\mathrm{DCAD} /$ CON had increased milk yield from d 0 to 30 (45.9 \pm 1.8 and $45.4 \pm 1.8 \mathrm{~kg}$, respectively) compared with the $+\mathrm{DCAD} / \mathrm{CON}$ and $-\mathrm{DCAD} / 5-\mathrm{HTP}$ groups $(41.0$ \pm 1.8 and $41.5 \pm 1.9 \mathrm{~kg}$, respectively). No DCAD or 5 -HTP effects were observed $(P>0.05)$. Mean milk yield on d 30 across all groups was $52.74 \pm 1.21 \mathrm{~kg}$ and did not differ between treatment groups.

\section{$D M I$ and $B W$}

Dry matter intake (Figure 5B) decreased in all groups $(P<0.0001)$ during the prepartum period. No 


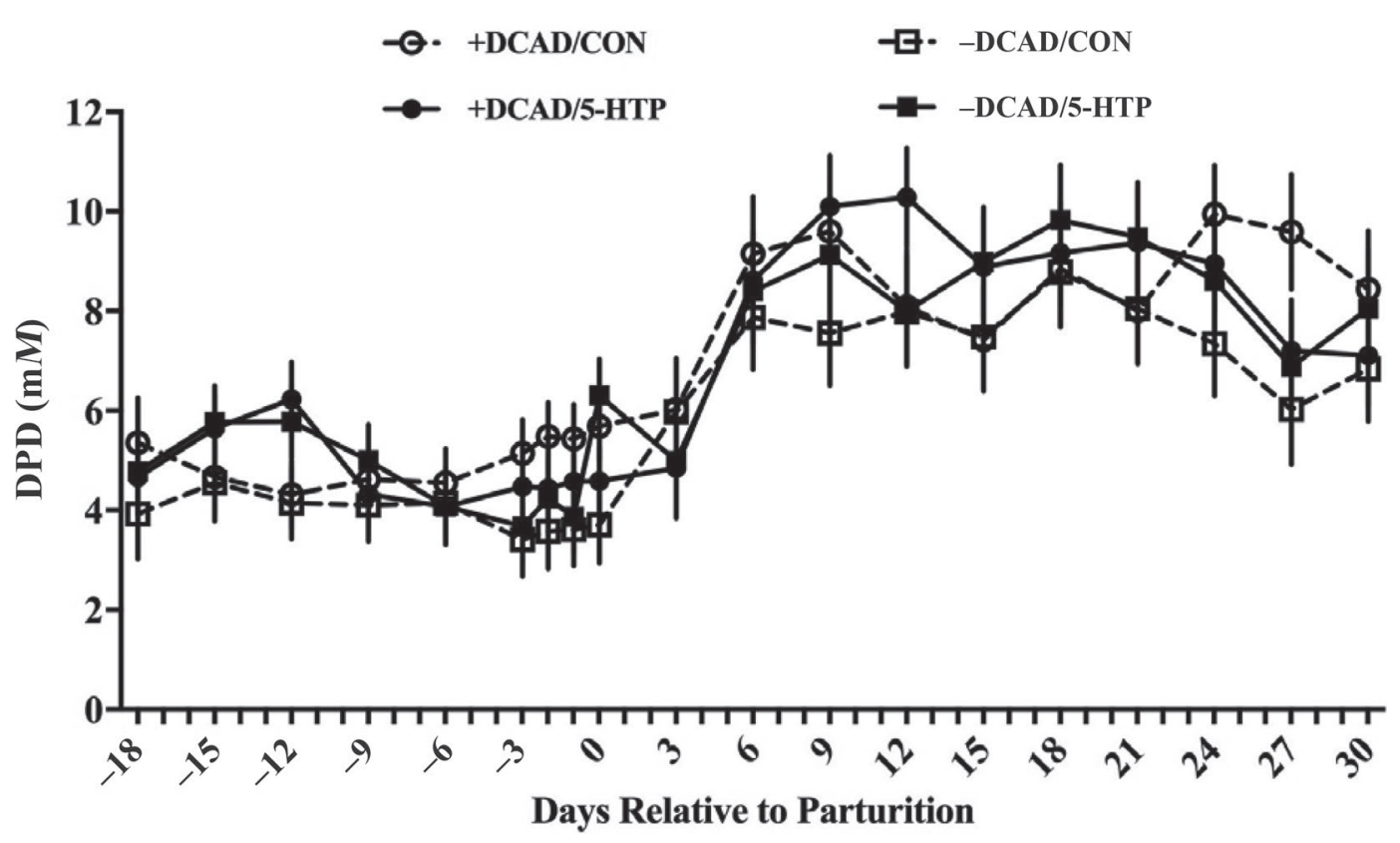

Figure 4. Effects of feeding a negative DCAD diet to multiparous Holstein dairy cows in combination with the delivery of 5-hydroxy-Ltryptophan (5-HTP) on urine deoxypyridinoline (DPD) concentrations. No significant prepartum effects were observed due to time, DCAD, 5 -HTP, or DCAD $\times 5$-HTP $(P>0.05)$. The only significant effect was during the postpartum period and was due to day: $P<0.0001$. Data represent the $\mathrm{LSM} \pm \mathrm{SEM}$. CON $=$ saline.

DCAD by 5 -HTP interaction was observed $(P>0.05)$. However, there was a prepartum tendency for a 5-HTP by day interaction $(P=0.05)$, and a DCAD by 5 -HTP by day interaction $(P=0.05)$, with $-\mathrm{DCAD} / 5$-HTP having the lowest DMI. These interactions were not present in the postpartum period. Postpartum DMI increased $(P<0.0001)$ from d 0 to 30 of lactation. Prepartum DMI averaged $13.5 \pm 0.8,14.2 \pm 0.7,14.4 \pm$ 0.7 , and $12.1 \pm 0.8 \mathrm{~kg}$ for $+\mathrm{DCAD} / \mathrm{CON},+\mathrm{DCAD} / 5-$ HTP, -DCAD/CON, -DCAD/5-HTP, respectively. Postpartum DMI of the lactation diet averaged 22.5 $\pm 1.0,22.6 \pm 1.0,23.3 \pm 1.0$, and $22.0 \pm 1.1 \mathrm{~kg}$ for $+\mathrm{DCAD} / \mathrm{CON},+\mathrm{DCAD} / 5-\mathrm{HTP},-\mathrm{DCAD} / \mathrm{CON},-$ $\mathrm{DCAD} / 5$-HTP, respectively.

Weekly mean BW were not different between any of the 4 treatment groups during the entire experiment. Postpartum, a tendency was observed for all experimental groups to exhibit a decrease in mean BW $(P=$ $0.06)$, but no differences were observed between prepartum dietary treatments $(P>0.05)$ or 5 -HTP treatment $(P>0.05)$.

\section{Mammary Gland Gene Expression}

The mRNA expression of PTHrP, ORAI1, PMCA2, $S P C A 1, P C N A$, and $\alpha$-LA was not affected by diet or 5 -HTP treatment on $\mathrm{d} 1$ of lactation. On d 8 of lactation, mammary gland $P T H r P$ mRNA expression was increased approximately 30 -fold in the $+\mathrm{DCAD} / 5$ -
HTP $(P<0.001)$ and 40 -fold in the -DCAD $/ 5$-HTP $(P<0.001)$ treatment groups, respectively, compared with the $+\mathrm{DCAD} / \mathrm{CON}$ and $-\mathrm{DCAD} / \mathrm{CON}$ treatment groups (Figure 6A). The mRNA expression of the calcium pump ORAI1, which is located on the basolateral side of the mammary epithelium, was increased 4 -fold in the $-\mathrm{DCAD} / 5$-HTP treatment group compared with all other treatment groups $(P$ $<0.01$ ) on $\mathrm{d} 8$ of lactation (Figure $6 \mathrm{~B}$ ). The mRNA expression of the calcium pump located on the apical membrane, PMCA2, which is responsible for pumping approximately $60 \%$ of the calcium into milk, was increased 4 -fold in the $+\mathrm{DCAD} / 5$-HTP treatment group $(P<0.01)$ relative to all other treatment groups on d 8 of lactation (Figure $6 \mathrm{C}$ ). The calcium pump $S P C A 1$, which is responsible for pumping calcium in the Golgi apparatus to facilitate the binding of $\mathrm{Ca}^{2+}$ to casein, exhibited a 10-fold increase in mRNA expression in the $-\mathrm{DCAD} / 5$-HTP treatment group on $\mathrm{d} 8$ lactation relative to the $+\mathrm{DCAD} / \mathrm{CON}$ and $-\mathrm{DCAD} /$ CON treatment groups $(P<0.05$; Figure $6 \mathrm{D})$. The mRNA expression of a cell proliferation marker, PCNA, was increased 6 -fold in the -DCAD/5-HTP treatment group on $\mathrm{d} 8$ lactation relative to the $+\mathrm{DCAD} / \mathrm{CON}$ and $-\mathrm{DCAD} / \mathrm{CON}$ treatment groups $(P<0.01$; Figure $6 \mathrm{E})$. Finally, mRNA expression of $\alpha-\mathrm{LA}$ was increased approximately 100 -fold in both the $+\mathrm{DCAD} / 5$-HTP $(P<0.05)$ compared with the $+\mathrm{DCAD} / \mathrm{CON}$ and $\mathrm{DCAD} / \mathrm{CON}$ treatment groups and in $-\mathrm{DCAD} / 5-\mathrm{HTP}$ 


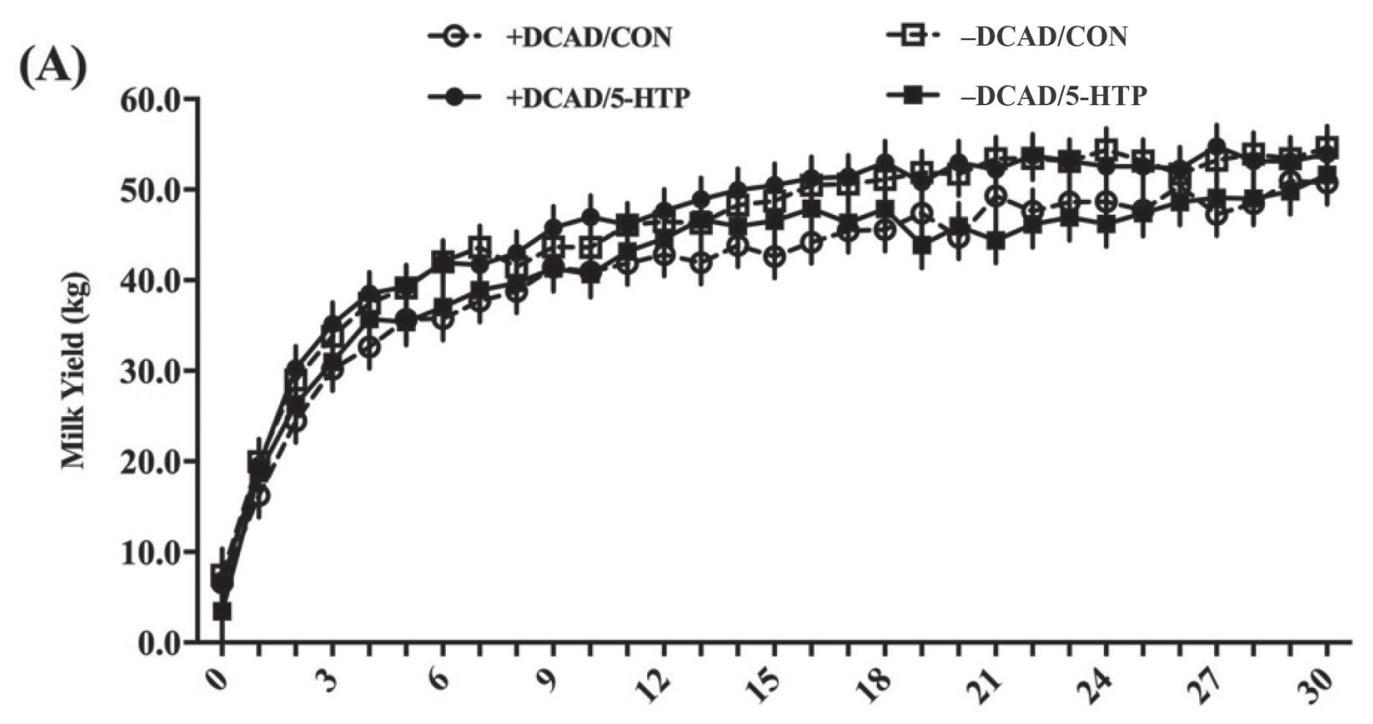

(B)

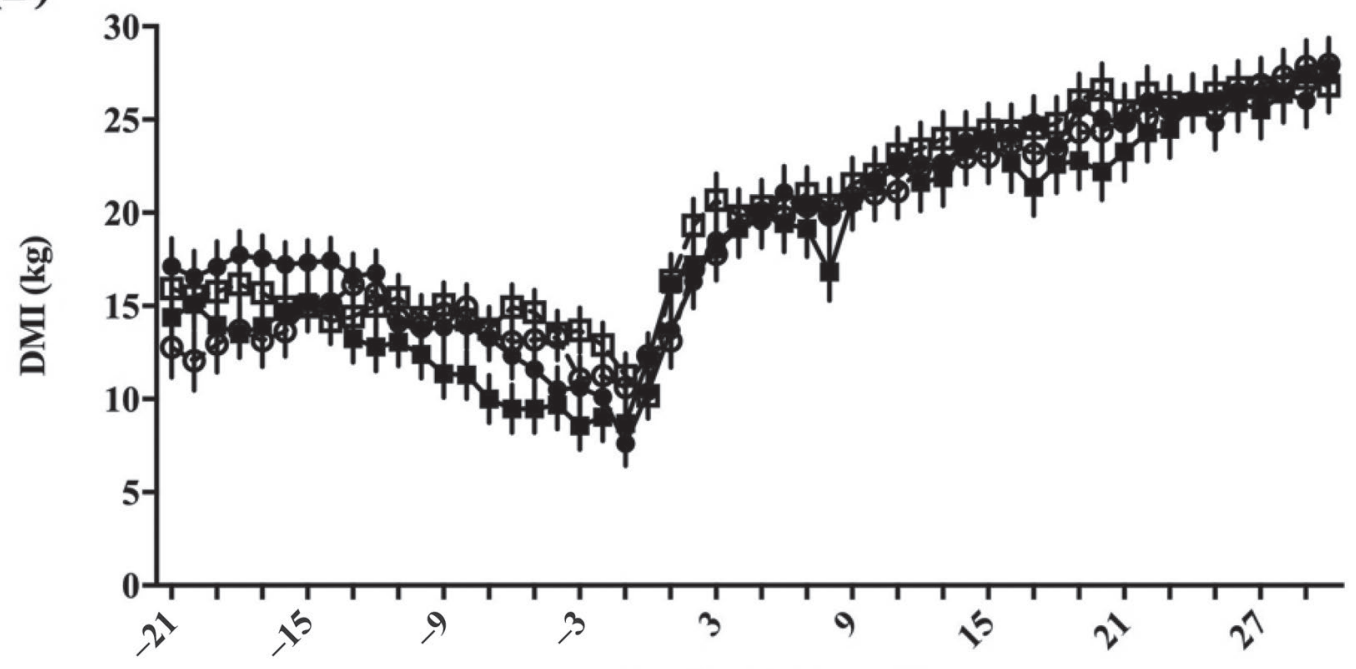

Days Relative to Parturition

Figure 5. Effects of feeding a negative DCAD diet to multiparous Holstein dairy cows in combination with the delivery of 5-hydroxy-Ltryptophan (5-HTP) on daily milk yield (A) and DMI (B). For milk yield, a significant overall effect of day $(P<0.0001)$ and an overall DCAD $\times 5$-HTP interaction $(P<0.05)$ were observed. For DMI, significant day effects were observed prepartum and postpartum (both $P<0.0001)$. Data represent $\mathrm{LSM} \pm \mathrm{SEM}$. CON $=$ saline.

compared with + DCAD $/$ CON cows $(P<0.01)$ and the $-\mathrm{DCAD} / \mathrm{CON}$ treatment group $(P<0.05$; Figure $6 \mathrm{~F})$.

\section{DISCUSSION}

The rapidly increasing demand for $\mathrm{Ca}$ at the onset of lactation poses a great risk for a high-producing dairy cow. It has been shown that any delay in achieving and maintaining $\mathrm{Ca}$ homeostasis during the early lactation period increases the cow's risk for additional adverse health events, potentially leading to compromised production and increased risk of involuntary culling or even death. Although incidence of clinical hypocalce- mia has dramatically decreased with the introduction of -DCAD diets, subclinical hypocalcemia remains a prevalent issue in the industry (Block, 1984; Reinhardt et al., 2011; Rodriguez et al., 2017). In this study, we demonstrate that a prepartum -DCAD diet in combination with prepartum supplemental 5-HTP has a positive effect on periparturient $\mathrm{iCa}$ and tCa concentrations when compared with the other 3 treatments and that the $-\mathrm{DCAD} / \mathrm{CON}$ and $+\mathrm{DCAD} / 5$-HTP treatment groups had increased tCa concentrations compared with the $+\mathrm{DCAD} / \mathrm{CON}$ group, but were similar to each other. These data suggest that the $-\mathrm{DCAD} / \mathrm{CON}$ and $+\mathrm{DCAD} / 5$-HTP have similar effects on tCa concen- 
(A)

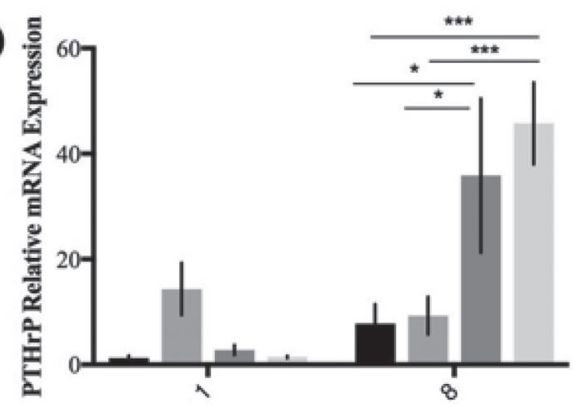

(C)

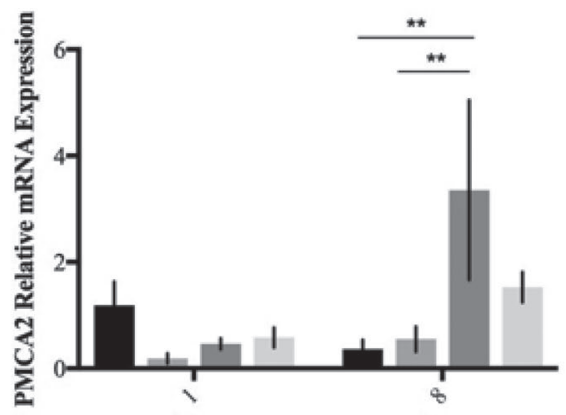

(E)

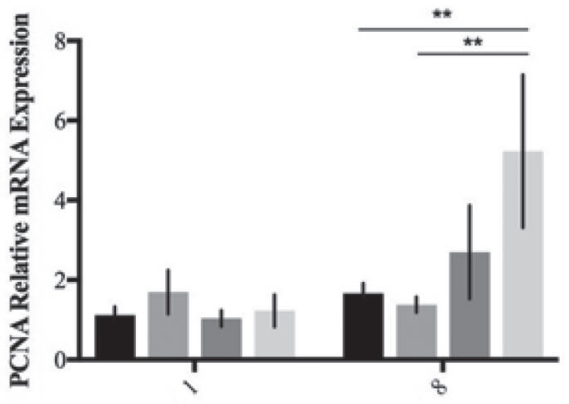

Days Relative to Parturition (d 0)
+DCAD/CON

-DCAD/CON

+DCAD/5-HTP

-DCAD/5-HTP
(B)

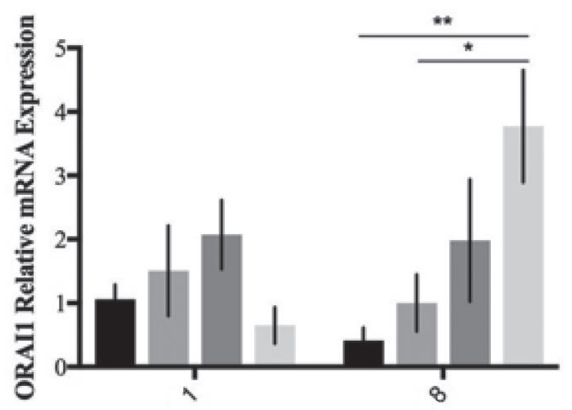

(D)

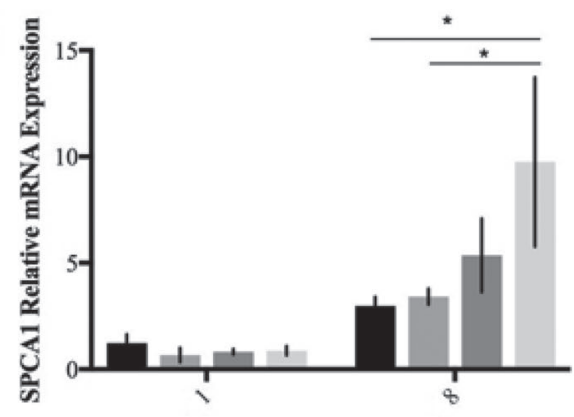

(F)

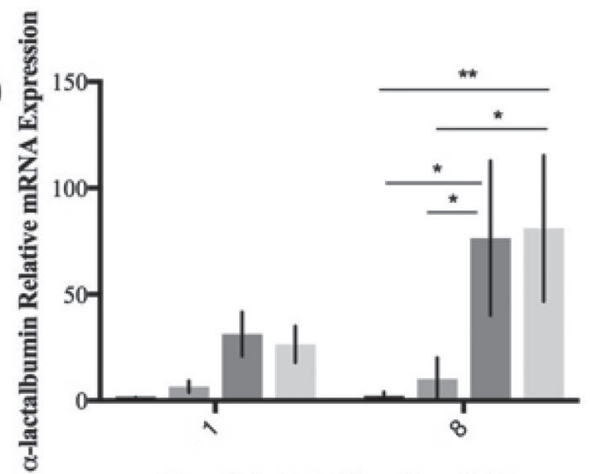

Days Relative to Parturition (d 0)

Figure 6. Effects of feeding a negative DCAD diet to multiparous Holstein dairy cows in combination with the delivery of 5-hydroxy-L-tryptophan (5-HTP) prepartum on mammary gland gene expression on d 1 and 8 of lactation. (A) Parathyroid hormone related-protein (PTHrP) relative mRNA expression, (B) calcium release-activated calcium channel protein (ORAI1) relative mRNA expression, (C) plasma membrane $\mathrm{Ca}^{2+}$ ATPase 2 (PMCA2) relative mRNA expression, (D) secretory pathway $\mathrm{Ca}^{2+}$ ATPase isoform 1 (SPCA1) relative mRNA expression, (E) proliferating cell nuclear antigen (PCNA) mRNA expression, and (F) $\alpha$-LA relative mRNA expression. The geometric means of ribosomal protein 15 (RPS15), cyclophilin A (CYCLOA), and hypoxanthine phosphoribosyltransferase 1 (HPRT1) were used as housekeeping genes, and analysis was conducted using the $2^{-\Delta \Delta \mathrm{Ct}}$ method (Livak and Schmittgen, 2001) using the $+\mathrm{DCAD} / \mathrm{CON}$ mammary gland samples collected on $\mathrm{d} 1$ of lactation as the experimental control. $\mathrm{CON}=$ saline. Data represent the LSM and SEM. ${ }^{*} P<0.05 ;{ }^{* *} P<0.01 ; * * * P<0.001$.

trations at calving, and when combining a -DCAD diet with 5-HTP treatment, a further increase in tCa concentrations occurs.

A notable response was evident in the blood iCa concentrations (Figure 1B). Baseline measurements of iCa were collected before the start of 5-HTP infusions, and although no difference was observed between any of the 4 treatment groups before 5-HTP administration, a diet by treatment interaction $(P<0.05)$ was observed throughout the entire prepartum treatment period, with the highest iCa concentrations in - DCAD/5HTP cows. We did note that the $-\mathrm{DCAD} / \mathrm{CON}$ and + DCAD/5-HTP cows had similar iCa and tCa at parturition and the $+\mathrm{DCAD} / \mathrm{CON}$ had the lowest $\mathrm{iCa}$ 
and tCa concentrations at parturition. This suggests that 5-HTP can be used in conjunction with a -DCAD diet to potentially further improve $\mathrm{Ca}$ concentrations during the peripartum period and that 5-HTP alone and -DCAD without administration of 5-HTP. In our experiment, $-\mathrm{DCAD}$ alone had a similar effect on the improvement of $\mathrm{Ca}$ concentrations in relation to the cows on a + DCAD diet and receiving no 5-HTP. Interestingly, however, tCa remained unchanged prepartum across all treatment groups until $\mathrm{d} 0$. This is of great interest due to the fact that most hypocalcemia studies have examined only tCa concentrations in the blood (Sweeney et al., 2014). Our data demonstrate a clear shift in the amount of iCa concentrations in the blood prepartum in the $-\mathrm{DCAD} / 5-\mathrm{HTP}$ cows. This is an important finding, as iCa is the main form of $\mathrm{Ca}$ used by the cow to modulate $\mathrm{Ca}$ homeostasis (Goff, 2014). Currently, tCa is the main component evaluated to assess Ca status in dairy cows. Our data suggest that iCa should be looked at more closely when assessing Ca status in dairy cows. One hypothesis regarding this change in the iCa to tCa ratio is that more $\mathrm{Ca}$ is bound to protein because acidosis/alkalosis affects Ca binding to existing proteins in blood, which could lead to the inability to detect differences in Ca status when measuring tCa (Goff, 2014). However, in our study we did not measure total blood protein concentrations. More research is needed to better understand the importance of the distribution of $\mathrm{tCa}$ and $\mathrm{iCa}$ in the blood, and what this means for maintenance of $\mathrm{Ca}$ homeostasis during the peripartum period.

Additionally, DPD concentrations increased postpartum in all treatment groups. Although significant differences between groups were not observed, a large spike in the -DCAD/5-HTP group was seen in the $3 \mathrm{~d}$ prepartum as compared with the other treatment groups where a more gradual increase occurred. This observation should be further explored in future studies to determine how the interaction of $-\mathrm{DCAD} / 5$-HTP affects bone turnover. Numerous studies across species have shown that urine DPD concentrations are reflective of bone degradation, and that the protein is conserved across species, making the tests reliable (Robins et al., 1996; Rubinacci et al., 1999; Liesgang, 2003). Analysis of additional biomarkers of bone resorption, such as serum CTX and osteocalcin, may provide more valuable information with regard to bone mobilization and turnover in the future. It is also important to note that, whereas bone mobilization is critical in mitigating hypocalcemia, intestinal Ca absorption and increased Ca reabsorption from the kidneys are also important. It is possible that serotonin could also be acting directly at the level of the gut or kidney to modulate Ca homeostasis in addition to the effects of serotonin on the mammary gland (Yadav et al., 2008). Previous research has indicated that whereas a negative DCAD diet increased serotonin in the circulation, there was no effect of vitamin D treatment on circulating serotonin concentrations (Rodney et al., 2018). Therefore, the increase in tCa that is seen on $\mathrm{d} 0$ and 1 in the $-\mathrm{DCAD} / 5$ HTP cows may be due to the overall improvement of Ca homeostasis, including an increase in Ca uptake from the gut as well as an increase in Ca reabsorption from the kidneys. However, we did not measure $\mathrm{Ca}$ in the urine or feces. We did observe a significant increase in mRNA expression of PTHrP (Figure 6A) in the mammary gland on $\mathrm{d} 8$ of lactation in both the DCAD/5-HTP and +DCAD/5-HTP treatment groups compared with both the $+\mathrm{DCAD}$ and $-\mathrm{DCAD} / \mathrm{CON}$ treatment groups. It is interesting that our observed changes in mRNA expression occurred 1 wk after the start of lactation, as compared with immediately at parturition. This supports our hypothesis as well as previous research in rodents where we observed similar results on d 10 of lactation, that serotonin regulates calcium homeostasis during lactation through induction of PTHrP in the mammary gland (Hernandez et al., 2012; Laporta et al., 2014b). It is possible that we may be improving long-term calcium imbalance during early lactation, but further studies need to be done to fully elucidate the timing and effects of serotonin on hypocalcemia and calcium homeostasis during early lactation. Additionally, we observed increased mRNA expression of ORAI1 in the -DCAD/5-HTP treatment group, which is the calcium channel found on the basolateral membrane of the mammary gland responsible for uptake of calcium. Increased mRNA expression of PMCA2 occurred in the $+\mathrm{DCAD} / 5-\mathrm{HTP}$ treatment group, which is the calcium pump on the apical membrane of the mammary gland that actively pumps $60 \%$ of calcium into milk. Finally, SPCA1 mRNA expression was elevated in the $-\mathrm{DCAD} / 5$-HTP treatment group, which is critical for attaching $\mathrm{Ca}^{2+}$ to casein in the Golgi of the mammary epithelium (Cross et al., 2014; Figure 6). These data suggest that 5-HTP treatment stimulates calcium movement and potentially flux in the mammary gland during mature milk production, which may lead to increased PTHrP production by the mammary gland. However, this should be more thoroughly explored in the bovine mammary gland. It is also important to note that for PTHrP, ORAI1, and SPCA1, the -DCAD diet and 5-HTP appeared to have a somewhat synergistic effect on these genes, as the DCAD/CON treatment did not have significant effects on mRNA expression of the genes measured. We have previously shown in the rodent model that the effect of serotonin on calcium homeostasis in the mammary gland may be due to an epigenetic mechanism (Laporta 
et al., 2014b); however, we have not fully delineated these pathways in the cow at this time. This could be a potential explanation for the temporal effects on gene expression we observe in our study; however, we must investigate this further.

As expected based on previous DCAD research, feeding a -DCAD diet or infusion of 5-HTP to a + DCAD diet had a positive effect on tCa at parturition (Figure 1A). Despite analyzed dietary DCAD being -5.5 and +14 , rather than the targeted -13 and +13 , we saw that use of the negative DCAD was still sufficient in decreasing urinary and blood $\mathrm{pH}$ as one would expect of this dietary strategy (Block, 1984; Goff, 2014). Because we were only analyzing pooled feed samples weekly, this is an expected result. Feeding the -DCAD diet did not negatively affect DMI (Figure 5B) prepartum or postpartum. Although palatability has historically been a concern, introduction of specifically designed products to create - DCAD diets have mitigated this issue (DeGroot et al., 2010). In this experiment, the 5-HTP treated cows had a slight decrease in DMI likely due to intravenous administration of 5-HTP, which we have previously shown decreases stool consistency (Laporta et al., 2015; Weaver et al., 2016). At this time, we are unable to feed 5-HTP in the diet because we are unaware of the ability of 5-HTP to bypass the rumen without protection. However, based on rodent studies, we would expect to see no change in DMI, or reduction in stool consistency if 5-HTP was administered through the diet (Laporta et al., 2013).

In this study, we have confirmed that 5-HTP infusions were effective in elevating circulating serotonin concentrations (Figure 3). This is consistent with our previous experiments in dairy cows (Laporta et al., 2015; Weaver et al., 2016). It is likely that the elevated postpartum serotonin concentrations in the cows treated prepartum with 5-HTP was due to serotonin being taken up by the platelets in these cows. The platelets are capable of converting 5-HTP to serotonin as they possess aromatic AA decarboxylase and they also have been shown to accumulate 5-HTP when 5-HTP was administered to humans (Magnussen and Van Woert, 1982). Further evaluation of this phenomenon is needed in our model. We also demonstrated that the -DCAD level in the prepartum diet was appropriately applied and consumed based on the reduced urine $\mathrm{pH}$ levels (Figure 2A). In addition, the response in the blood $\mathrm{pH}$ (Figure 2B) of the cows receiving the -DCAD diets was similar to what has been described in the literature (Goff, 2008). Somewhat unexpectedly, we saw a further decrease in the blood $\mathrm{pH}$ among cows in the DCAD/5-HTP treatment group. This finding warrants further research.
Weekly BW, daily DMI, and blood hematocrit levels would suggest that no negative health effects were elicited by either the prepartum diet, 5-HTP treatment, or the combination of the two. Also, with a numerical decrease observed in adverse health events, we would suggest the overall health of the cows at parturition appeared to improve with the combination of the -DCAD diet and 5-HTP treatment. Due to inadequate sample size to measure binomial outcomes, we are unable to analyze health outcomes statistically.

Furthermore, we did not observe any differences in milk yield between treatments (Figure 5A). Interestingly, we did observe a significant increase in mammary gland $\alpha$-LA mRNA expression in the $-\mathrm{DCAD} / 5-\mathrm{HTP}$ and + DCAD $/ 5$-HTP treatment groups on d 8 of lactation (Figure 6F). Previous research suggests that serotonin, at high concentrations, decreases $\alpha$-LA mRNA expression in mammary epithelial cell culture, as well as when given at a high dose in an intramammary infusion (Matsuda et al., 2004; Hernandez et al., 2008, 2009). Serotonin is known to have biphasic effects on tight junctions in the mammary gland (Stull et al., 2007; Pai and Horseman, 2008). It is possible that the biphasic regulation by serotonin could be true for milk protein gene expression as well. Additionally, we saw a significant increase in PCNA mRNA expression, a cell proliferation marker, in the -DCAD/5-HTP group and a numerical increase in the +DCAD/5-HTP group in the mammary gland on d 8 of lactation. Previous data have shown that at high concentrations, serotonin can increase mammary epithelial cell apoptosis and cell shedding (Pai and Horseman, 2011). Mice deficient in the rate-limiting step for serotonin synthesis, tryptophan hydroxylase 1, have decreased mammary epithelial cell proliferation, an effect that was rescued by administration of 5-HTP (Laporta et al., 2014a). Therefore, the effects of serotonin on mammary gland function appear to be dependent on concentration and timing. We were surprised that we only observed effects on $\mathrm{d} 8$ of lactation and not d 1. It is possible that based on our previous data in rodents (Laporta et al., 2014b), where we observed epigenetic effects on the sonic hedgehog promoter in the mammary gland, could extend to other genes and result in temporal effects on gene expression. However, much more research is needed in this area. It is interesting that the genes related to cell proliferation, milk protein production, and calcium flux through mammary gland were improved with 5-HTP treatment on d 8 of lactation, suggesting a potential for improved milk synthesis by the mammary gland itself.

Based on the mechanism by which a -DCAD diet functions to improve $\mathrm{Ca}$, it is likely that we would 
see the same improvement in binding potential of the PTHrP molecule to this receptor. This is based on the fact that PTHrP uses the PTH-receptor to elicit its action (Wysolmerski, 2012). Although we did not measure circulating PTHrP in this experiment, we would expect that the increase in serotonin resulted in an increase in circulating concentrations of PTHrP. We have previously shown in several studies that serotonin increased PTHrP expression in the mammary gland and secretion into the circulation on d 10 of lactation in rodents (Hernandez et al., 2012b; Laporta et al., 2014). We have not measured PTHrP concentrations in cows in response to 5 -HTP to date; however, our observational study demonstrated that PTHrP concentrations were elevated on $\mathrm{d} 1$ to 2 postpartum in dairy cows (Moore et al., 2015). Future studies will aim to explore the relationship between PTHrP production by the mammary gland in response to 5-HTP treatment in dairy cows. We did observe increased mRNA expression of PTHrP on $\mathrm{d} 8$ of lactation in the mammary gland of both the -DCAD and +DCAD/5-HTP treatment groups. Future research will need to explore the timing of 5-HTP treatment on modulation of mammary gland $\mathrm{Ca}$ homeostasis and production of PTHrP. In a recent experiment, it was demonstrated that administration of 5-HTP prepartum increased tCa concentrations from d 0 to 4 postpartum but did not cause a change in $\mathrm{PTH}$ concentrations (Hernandez-Castellano et al., 2017a). Interestingly, PTH concentrations were elevated in the control cows of this previous experiment, who had lower serum tCa concentrations on d 0 to 4 postpartum (Hernandez-Castellano et al., 2017b). Furthermore, 1-25 dihyxdroxyvitamin $\mathrm{D}$ concentrations in this same experiment were only elevated in control cows and not the 5-HTP-treated cows (Rupert Bruckmaier, University of Bern, Bern, Switzerland, personal communication). Additionally, in a recently published set of experiments in which the interaction of DCAD with varying vitamin D supplements prepartum demonstrated no effect of vitamin D supplementation on circulating serotonin concentrations (Rodney et al., 2018). This supports our working hypothesis that serotonin interacts with PTHrP production in the mammary gland during lactation to improve Ca homeostasis, rather than acting through the canonical PTH pathway to regulate Ca metabolism. However, future research needs to discern the exact molecular mechanisms and timing of 5-HTP treatment on PTHrP and Ca dynamics in the mammary gland during lactation.

In conclusion, administration of 5-HTP is most effective in combination with a -DCAD diet. This resulted in an increase in $\mathrm{iCa}$ and tCa concentrations around the time of parturition, therefore improving periparturient maternal Ca homeostasis. Feeding a -DCAD diet alone, and providing 5-HTP in combination with a + DCAD diet, resulted in similar increases in tCa concentrations during the periparturient period compared with feeding a + DCAD diet without any 5-HTP supplementation. Additionally, research will need to explore the possibility of feeding 5-HTP to dairy cows, rather than intravenous administration. Future research is needed to determine the direct effects of 5 -HTP on blood $\mathrm{pH}$ and the mechanism whereby 5-HTP and -DCAD diets interact.

\section{ACKNOWLEDGMENTS}

This project was funded in part by the competitive grant \#2016-67015-34584 from the National Institute of Food and Agriculture/United States Department of Agriculture (Washington, DC) and Arm and Hammer Animal Nutrition (Princeton, NJ).

\section{REFERENCES}

Block, E. 1984. Manipulating dietary anions and cations for prepartum dairy cows to reduce incidence of milk fever. J. Dairy Sci. 67:2939-2948

Chamberlin, W. G., J. R. Middleton, J. N. Spain, G. C. Johnson, M. R. Ellersieck, and P. Pithua. 2013. Subclinical hypocalcemia, plasma biochemical parameters, lipid metabolism, postpartum disease, and fertility in postparturient dairy cows. J. Dairy Sci. 96:7001-7013.

Cross, B. M., G. E. Breitwieser, T. A. Reinhardt, and R. Rao. 2014. Cellular calcium dynamics in lactation and breast cancer: from physiology to pathology. Am. J. Physiol. Cell Physiol. 306:C515C526.

DeGroot, M. A., E. Block, and P. D. French. 2010. Effect of prepartum anionic supplementation on periparturient feed intake, health, and milk production. J. Dairy Sci. 93:5268-5279.

Goff, J. P. 2008. The monitoring, prevention, and treatment of milk fever and subclinical hypocalcemia in dairy cows. Vet. J. 176:50-57.

Goff, J. P. 2014. Calcium and magnesium disorders. Vet. Clin. North Am. Food Anim. Pract. 30:359-381.

Guard, C. L. 1996. Fresh cow problems are costly; culling hurts the most. Hoard's Dairyman 141:8.

Hare, E., H. D. Norman, and J. R. Wright. 2006. Survival rates and productive herd life of dairy cattle in the United States. J. Dairy Sci. 89:3713-3720.

Hernandez, L. L., K. A. Gregerson, and N. D. Horseman. 2012. Mammary gland serotonin regulates parathyroid hormone-related protein and other bone-related signals. Am. J. Physiol. Endocrinol. Metab. 302:E1009-E1015.

Hernandez, L. L., S. W. Limesand, J. L. Collier, N. D. Horseman, and R. J. Collier. 2009. The bovine mammary gland expressed multiple functional isoforms of serotonin receptors. J. Endocrinol. 203:123-131.

Hernandez, L. L., C. M. Stiening, J. B. Wheelock, L. H. Baumgard, A. M. Parkhurst, and R. J. Collier. 2008. Evaluation of serotonin as a feedback inhibitor of lactation in the bovine. J. Dairy Sci. 91:1834-1844.

Hernandez-Castellano, L. E., L. L. Hernandez, H. Sauerwein, and R. M. Bruckmaier. 2017b. Endocrine and metabolic changes in transition dairy cows are affected by prepartum infusions of a serotonin precursor. J. Dairy Sci. 100:5050-5057.

Hernandez-Castellano, L. E., L. L. Hernandez, S. Weaver, and R. M. Bruckmaier. 2017a. Increased serum serotonin improves parturient calcium homeostasis in dairy cows. J. Dairy Sci. 100:1580-1587. 
Horst, R. L., J. P. Goff, and T. A. Reinhardt. 2005. Adapting to the transition between gestation and lactation: Differences between rat, human and dairy cow. J. Mammary Gland Biol. Neoplasia 10:141-156.

Horst, R. L., J. P. Goff, T. A. Reinhardt, and D. R. Buxton. 1997. Strategies for preventing milk fever in dairy cattle. J. Dairy Sci. 80:1269-1280.

Kovacs, C. S. 2017. The skeleton is a storehouse of mineral that is plundered during lactation and (fully?) replenished afterwards. J. Bone Miner. Res. 32:676-680.

Laporta, J., K. P. Keil, C. M. Vezina, and L. L. Hernandez. 2014a. Peripheral serotonin regulates maternal calcium trafficking in mammary epithelial cells during lactation in mice. PLoS One 9:e110190.

Laporta, J., K. P. Keil, S. R. Weaver, C. M. Cronick, A. P. Prichard T. D. Crenshaw, G. W. Heyne, C. M. Vezina, R. J. Lipinski, and L. L. Hernandez. 2014b. Serotonin regulates calcium homeostasis in lactation by epigenetic activation of hedgehog signaling. Mol. Endocrinol. 28:1866-1874.

Laporta, J., S. A. E. Moore, S. R. Weaver, C. M. Cronick, M. Olsen, A. P. Prichard, B. P. Schnell, T. D. Crenshaw, F. Penagaricano, R. M. Bruckmaier, and L. L. Hernandez. 2015. Increasing serotonin concentrations alter calcium and energy metabolism in dairy cows. J. Endocrinol. 226:43-55.

Laporta, J., T. L. Peters, S. R. Weaver, K. E. Merriman, and L. L. Hernandez. 2013. Feeding 5-hydroxy-L-tryptophan during the transition from pregnancy to lactation increases calcium mobilization from bone in rats. Domest. Anim. Endocrinol. 44:176-184.

Liesgang, A. 2003. Possibilities of monitoring bone metabolism in ruminants-An overview of the methods in use. Acta Vet. Scand. $97: 23-28$.

Livak, K. J., and T. D. Schmittgen. 2001. Analysis of gene expression data using real-time quantitative PCR and the 2(-delta delta $\mathrm{C}(\mathrm{T})$ ). Methods 25:402-408.

Magnussen, I., and M. H. Van Woert. 1982. Human pharmacokinetics of long term 5-hydroxytryptophan combined with decarboxylase inhibitors. Eur. J. Clin. Pharmacol. 23:81-86.

Mather, K. J., C. L. Chik, and B. Corenblum. 1999. Maintenance of serum calcium by parathyroid hormone-related peptide during lactation in a hypoparathyroid patient. J. Clin. Endocrinol. Metab. 84:424-427.

Matsuda, M., T. Imaoka, A. J. Vomachka, G. A. Gudelsky, Z. Hou, M. Mistry, J. P. Bailey, K. M. Nieport, D. J. Walther, M. Bader, and N. D. Horseman. 2004. Serotonin regulated mammary gland development via an autocrine-paracrine loop. Dev. Cell 6:193-203.

Moore, S. A., J. Laporta, T. D. Crenshaw, and L. L. Hernandez. 2015. Patterns of circulating serotonin and related metabolites in multiparous dairy cows in the peripartum period. J. Dairy Sci. 98:3754-3765.

Moseley, J. M., M. Kubota, H. Diefenbachjagger, R. E. H. Wettenhall, B. E. Kemp, L. J. Suva, C. P. Rodda, P. R. Ebeling, P. J. Hudson, J. D. Zajac, and T. J. Martin. 1987. Parathyroid hormone-related protein purified from human lung cancer cell-line. Proc. Natl. Acad. Sci. USA 84:5048-5052.

NRC. 2001. Nutrient Requirements of Dairy Cattle. 7th rev. ed. Natl. Acad. Press, Washington, DC.

Pai, V. P., and N. D. Horseman. 2008. Biphasic regulation of mammary epithelial resistance by serotonin through activation of multiple pathways. J. Biol. Chem. 283:30901-30910.

Pai, V. P., and N. D. Horseman. 2011. Multiple cellular responses to serotonin contribute to epithelial homeostasis. PLoS One 6:e17028.

Reinhardt, T. A., J. D. Lippolis, B. J. McCluskey, J. P. Goff, and R. L. Horst. 2011. Prevalence of subclinical hypocalcemia in dairy herds. Vet. J. 188:122-124.
Riond, J. L., N. Kocabagli, F. Cloux, and M. Wanner. 1996. Parathyroid hormone-related protein in the colostrum of paretic post parturient dairy cows. Vet. Rec. 138:333-334.

Robins, S. P., A. Duncan, N. Wilson, and B. J. Evans. 1996. Standardization of pyridinium crosslinks, pyridinoline and deoxypyridinoline, for use as biochemical markers of collagen degradation. Clin. Chem. 42:1621-1626.

Rodney, R. M., N. Martinez, E. Block, L. L. Hernandez, P. Celi, C. D. Nelson, J. E. P. Santos, and I. J. Lean. 2018. Effects of dietary cation-anion difference and source of vitamin D on dairy cows: Vitamin D, mineral and bone metabolism. J. Dairy Sci. 101:2519-2543.

Rodriguez, E. M., A. Aris, and A. Bach. 2017. Associations between subclinical hypocalcemia and postparturient diseases in dairy cows. J. Dairy Sci. 100:7427-7434

Rubinacci, A., R. Melzi, M. Zampino, A. Soldarini, and I. Villa. 1999 Total and free deoxypyridinoline after acute osteoclast activity inhibition. Clin. Chem. 45:1510-1516.

Seifi, H. A., S. J. LeBlanc, K. E. Leslie, and T. F. Duffield. 2011. Metabolic predictors of post-partum disease and culling risk in dairy cattle. Vet. J. 188:216-220.

Sowers, M. F., B. W. Hollis, B. Shapiro, J. Randolph, C. A. Janney, D. W. Zhang, M. A. Schork, M. Crutchfield, F. Stanczyk, and M. Russell Aulet. 1996. Elevated parathyroid hormone-related peptide associated with lactation and bone density loss. JAMA 276:549-554.

Stull, M. A., V. Pai, A. J. Vomachka, A. M. Marshall, G. A. Jacob, and N. D. Horseman. 2007. Mammary gland homeostasis employs serotonergic regulation of epithelial tight junctions. Proc. Natl. Acad. Sci. USA 104:16708-16713.

Sweeney, B. M., E. M. Martens, M. J. Felippe, and T. R. Overton. 2014. Impacts and evaluation of subclinical hypocalcemia in dairy cattle. Proceeding of the Cornell Nutrition Conference.

USDA. 2007. Dairy 2007, Part I: Reference of Dairy Cattle Health and Management Practices in the United States, 2007. Page 83. USDA-APHIS-VS, CEAH. Fort Collins, CO. \#N480.1007.

USDA. 2017. Electronic Research Service, Dairy Data. Accessed Mar. 5, 2017. https://www.ers.usda.gov/data-products/dairy-data/.

VanHouten, J. N., P. Dann, A. F. Stewart, C. J. Watson, M. Pollak, A. C. Karaphs, and J. J. Wysolmerski. 2003. Mammary-specific deletion of parathyroid hormone-related protein preserves bone mass during lactation. J. Clin. Invest. 112:1429-1436.

Wang, L., H. Erlandsen, J. Haavik, P. M. Knappskog, and R. C. Stevens. 2002. Three-dimensional structure of human tryptophan hydroxylase and its implications for the biosynthesis of the neurotransmitters serotonin and melatonin. Biochemistry 41:1256912574.

Weaver, S. R., A. P. Prichard, E. L. Endres, S. A. Newhouse, T. L. Peters, P. M. Crump, M. S. Akins, T. D. Crenshaw, R. M. Bruckmaier, and L. L. Hernandez. 2016. Elevation of circulating serotonin improves calcium dynamics in the peripartum dairy cow. J. Endocrinol. 230:105-123.

Wysolmerski, J. J. 2012. Parathyroid hormone-related protein: An update. J. Clin. Endocrinol. Metab. 97:2947-2956.

Yadav, V. K., J. J. Ryu, N. Suda, K. F. Tanaka, J. A. Gingrich, G. Schutz, F. H. Florieux, C. Y. Change, J. D. Zajac, K. L. Insogna, J. J. Mann, R. Hen, P. Ducy, and G. Karsenty. 2008. Lrp5 controls bone formation by inhibiting serotonin synthesis in the duodenum. Cell 135:825-837. 